2019-10-20

\title{
Effect of temperature gradient on transient thermal creep of heated and stressed concrete in transient state tests
}

Fan, $\mathrm{K}$

http://hdl.handle.net/10026.1/14605

10.1016/j.conbuildmat.2019.06.197

Construction and Building Materials

Elsevier

All content in PEARL is protected by copyright law. Author manuscripts are made available in accordance with publisher policies. Please cite only the published version using the details provided on the item record or document. In the absence of an open licence (e.g. Creative Commons), permissions for further reuse of content should be sought from the publisher or author. 


\title{
Effect of temperature gradient on transient thermal creep of heated and stressed concrete in transient state tests
}

\author{
Kunjie Fan ${ }^{\mathrm{a}, \mathrm{b}^{*}}$, Dawang Li ${ }^{\mathrm{a}}$, Long-yuan $\mathrm{Li}^{\mathrm{b}}$, Jiayu $\mathrm{Wu}^{\mathrm{c}}$ \\ ${ }^{a}$ Guangdong Provincial Key Laboratory of Durability for Maine Civil Engineering, Shenzhen \\ University, Shenzhen 518060, China \\ ${ }^{\mathrm{b}}$ School of Engineering, University of Plymouth, Plymouth PL4 8AA, UK \\ ${ }^{\mathrm{c}}$ MOE Key Laboratory of Disaster Forecast and Control in Engineering, Institute of Applied \\ Mechanics, Jinan University, Guangzhou 510632, China
}

\begin{abstract}
The stress-strain constitutive relation of concrete subjected to thermomechanical loads is extremely complicated since its deformation relies on the sequences in which the heat and loads are applied. Existing experiments demonstrated that the development of quasi-instantaneous transient thermal creep, generally referred to as TTC, was dependent on the virgin heating of a mechanically pre-loaded concrete specimen. However, the mechanism behind it is still not fully understood. In this paper, a numerical method is developed to analyze the stress fluctuation and corresponding plastic strain caused by the combination of pre-load and temperature gradient. The results show that the TTC calculated using existing semi-implicit methods is reasonable only at early stage but could be wrong at high temperatures. The sharp increase of TTC beyond around $500{ }^{\circ} \mathrm{C}$ observed in many tests could be attributed to the implicit inclusion of the extra plastic strain resulted from temperature gradient. By including the extra plastic strain generated at different temperature levels, a more accurate formula for calculating TTC is proposed.
\end{abstract}

Keywords: Concrete; Thermomechanical load; Temperature gradient; Transient 
thermal creep; Load induced thermal strain; Explicit model.

\section{Introduction}

When concrete is subjected to sufficient heat such as fire, the deterioration of its mechanical properties with elevated temperatures is extremely complicated, particularly for the case where the concrete is with repeated cycles of heating-cooling and loading-unloading under thermal exposure. The main challenge in analyzing this kind of problems is how to accurately formulate the TTC (transient thermal creep), which is caused by pre-load on the virgin heating.

Previous studies $[1,2,3,4]$ have demonstrated that the behavior of concrete loaded thermal-mechanically relies on the sequences in which heating and loading are applied. The free thermal expansion of concrete was reduced significantly when the concrete had a pre-compressive load before heating. Such a decrease has been generally regarded as an extra strain component called TTC, which is a special property unique to concrete. For a partially or totally constrained structural member, TTC could be beneficial in both mitigating compressive stresses and reducing tensile cracks yielded from the thermal incompatibility between cement matrix and aggregates $[5,6,7]$. At a high temperature TTC could be greater than the mechanical strain of the concrete, indicating that an unexpected additional deformation may appear in the loaded direction. Moreover, the existence of TTC could make concrete damage even worse during cooling phase since the TTC is largely irrecoverable. Therefore, how to accurately model TTC is crucial for the assessment of a heated and stressed concrete structure, especially when the structure is subjected to heating-cooling cycles. It has been demonstrated that any mechanical analysis of stressed and heated concrete structures, which ignores TTC, would bring erroneous results $[8,10]$.

The present of TTC was discovered in the experiment performed by Johansen et al. in 
the 1960s [11]. Over the last five decades, numerous experimental studies $[12,13,14,15,16,17,18,19,20]$ have confirmed the existence and the main features of the TTC phenomenon. Initially, TTC was treated as a quasi-instantaneous (timeindependent) phenomenon owing to the fact that only a very short time is needed for TTC to develop completely under stabilized temperature field. TTC was found to be strongly nonlinear with respect to temperature and comparatively proportional to the mechanical stress. Also, it was found that TTC develops only on the virgin heating with pre-load and is largely irreversible to temperature. However, despite a large number of experimental studies published on TTC, there are very few studies on developing physical models, which can describe its underlying mechanism since most of existing models were developed based on the experimental data by using regression methods.

To measure TTC in experiments and to evaluate the behavior of concrete at high temperatures, two types of uniaxial testing methods are often used, namely the thermalsteady state test and the transient state test, as shown in Fig.1. The specimen in the steady state test is heated uniformly to a pre-defined temperature before it is mechanically loaded, which is a traditional experimental method for obtaining the stress-strain relation of concrete at a high temperature. For the transient state test the specimen is mechanically pre-loaded before it is heated. In a simple term, the steady state test is characterized by heating first followed by the loading; whereas the transient state test is characterized by loading first followed by heating. Although these two methods have the same terminal state of external mechanical load and temperature, their yielded strains are different due to the different historical heating-loading paths. This difference is generally defined as TTC [21]. However, it is believed that part of this difference is the mechanical strain caused by the interaction between the temperature gradient and pre-load during the transient state test. This mechanical strain could be substantial for concrete with fast heating rate and could be calculated using coupled thermal and stress analysis method. The purpose of this paper is to develop a 
calculation method for this kind of mechanical strain and to examine its influence on the experimentally obtained TTC.

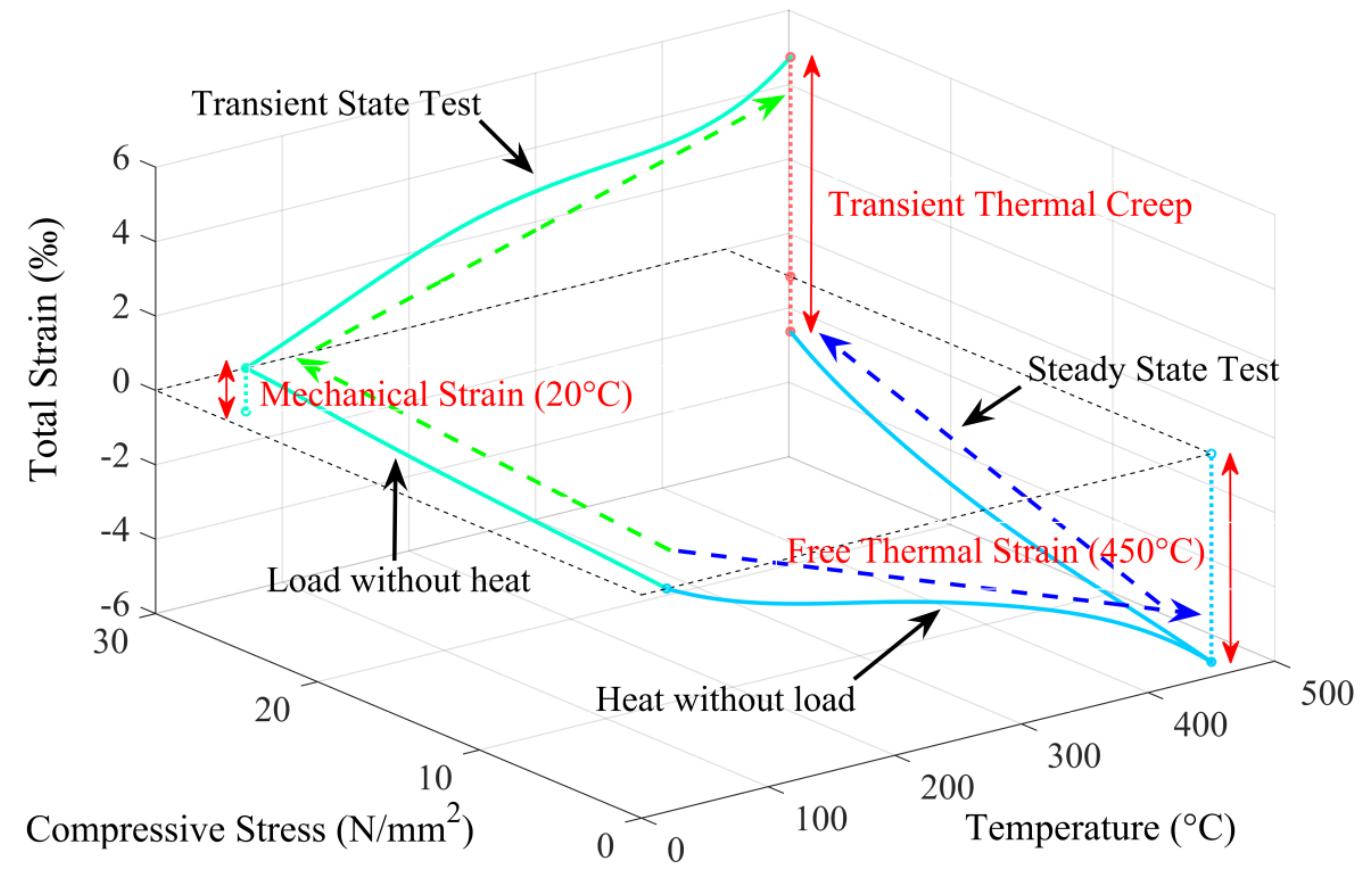

Fig.1. Definition of transient thermal creep and different test methods

As the definition, TTC is the difference between the strain measured in a transient state test and the strain measured in a corresponding steady state test. Thus, it is calculated from experimental results instead of being measured directly. Note that, the result obtained in a transient state test is the strain-temperature relationship at a constant stress level; whereas the result obtained in the steady state test is the stress-strain relationship at a constant temperature, which means that a pair of tests can give the estimation of TTC at one single point of the given constant temperature and constant stress. However, since TTC is a function of both temperature and mechanical stress, one has to perform a series of transient state tests with different pre-load levels and a series of steady state tests at different temperatures in order to obtain this function. 
In addition to the complex of experiments, another difficulty is how to distinct TTC accurately from other strain components. The free thermal strain can be measured by a reference transient test with $0 \%$ load level and the normal creep at high temperature could be neglected due to the short time of experiments. There is no disagreement on the analysis of these two components. The main argument is the mechanical strain in the transient state test. The mechanical strain can be divided into elastic and plastic parts, both of which vary with temperature and can be formulated by using the results obtained from corresponding steady state tests. The calculation of the elastic strain is relatively simple since it is only related to the mechanical stress and the temperaturedependent elastic modulus. In contrast, the calculation of the plastic strain is debatable. In some studies the plastic strain was assumed to be part of TTC $[22,23,24]$; while in others it was separated from TTC [1,25], but its calculation did not take into account the effect of temperature gradient.

\section{Review of semi-implicit models}

\subsection{Strain decomposition in transient state test}

Ideally, the specimen in a transient state test should have a uniformly distributed temperature increase. However, this is never achieved in practice. According to the experiment of Anderberg [1], even for a small cylinder specimen with only $75 \mathrm{~mm}$ diameter and $150 \mathrm{~mm}$ height, under a relatively low heating rate of $5^{\circ} \mathrm{C} / \mathrm{min}$, the largest temperature difference between its center and exposed surface in the transient state test could be more than $100{ }^{\circ} \mathrm{C}$. On the other hand, the specimen in a steady state test has normally had a uniformly distributed temperature before it is mechanically loaded. Therefore, except for the mechanical strain estimated by the steady state test directly, there is an extra mechanical strain component caused by the temperature gradient in the transient state test. Based on the explaination mentioned above, it can be concluded that 
there are three strain components yielded in concrete when it is under the action of thermal-mechanical load:

1) Free thermal strain $\varepsilon_{f t s}$ - that includes the thermal expansion strain due to increasing temperature and shrinkage strain caused by loss of water.

2) Mechanical strain $\varepsilon_{\sigma, T}$ - an instantaneous stress-related strain, which can be calculated by using the steady state constitutive model as follows,

$$
\varepsilon_{\sigma, T}=\varepsilon_{\sigma, 20^{\circ} \mathrm{C}}+\varepsilon_{\text {ela }, T}+\varepsilon_{p l a, T}+\varepsilon_{p l a, t g}
$$

where $\varepsilon_{\sigma, 20^{\circ} \mathrm{C}}$ is the initial mechanical strain caused by pre-load at ambient temperature, $\varepsilon_{e l a, T}$ and $\varepsilon_{p l a, T}$ are the additional elastic and plastic strains caused by the increase of temperature calculated from the steady state constitutive model, respectively, $\varepsilon_{p l a, t g}$ is the mechanical strain caused by temperature gradient in the transient state test.

3) Transient thermal creep $\varepsilon_{t t c}$ - an extra strain component in addition to $\varepsilon_{f t s}$ and $\varepsilon_{\sigma, T}$, which only happens in the virgin heating process of pre-loaded concrete and represents the effect of the specific historical loading and heating path.

Considering the short duration of the transient state test, the normal creep can normally be ignored. Thus, the decomposition of the total strain in a transient state test can be expressed as follows,

$$
\varepsilon_{\text {tot }}=\varepsilon_{f t s}+\varepsilon_{\sigma, 20^{\circ} \mathrm{C}}+\varepsilon_{\text {ela }, T}+\varepsilon_{p l a, T}+\varepsilon_{\text {pla }, t g}+\varepsilon_{\text {ttc }}
$$

\subsection{Semi-implicit inclusion of mechanical strain components in existing models}

Due to the difficulty of performing fire experiments, only several models have been established since 1970s. Table 1 gives a summary of these models [26,27,28]. The term of implicit used in Table 1 refers to the manner where the mechanical strain is formulated together with TTC and is calculated as the difference between the total strain developed in the transient state test and the free thermal strain. A typical example for 
this is the stress-strain relation given in Eurocode2 [29],

$$
\frac{\sigma}{\sigma_{c, T}}=\frac{\varepsilon_{\sigma, T}^{\prime}}{\varepsilon_{c, E C 2}} \frac{3}{2+\left(\frac{\varepsilon_{\sigma, T}^{\prime}}{\varepsilon_{c, E C 2}}\right)^{3}}
$$

where $\sigma$ is the applied stress, $\varepsilon_{\sigma, T}^{\prime}$ is the stress-related strain defined as the sum of mechanical strain and TTC, $\sigma_{c, T}$ is the peak stress at temperature T, and $\varepsilon_{c, E C 2}$ is the strain at peak stress at temperature $\mathrm{T}$.

Table1 Existing experimental methods and corresponding models

\begin{tabular}{|c|l|c|}
\hline Category & \multicolumn{1}{|c|}{ Model } & Authors \\
\hline Implicit & $\varepsilon_{t o t}=\varepsilon_{\sigma, T}^{\prime}+\varepsilon_{f t s}$ & Eurocode [26] \\
& $\varepsilon_{\sigma, T}^{\prime}=\varepsilon_{t o t}-\varepsilon_{f t s}=\varepsilon_{\sigma, T}+\varepsilon_{t t c}$ & \\
\hline Semi-implicit & $\varepsilon_{t o t}=\varepsilon_{l i t s}+\varepsilon_{\sigma, 20^{\circ} \mathrm{C}}+\varepsilon_{f t s}$ & Nielsen [27], \\
1 & $\varepsilon_{l i t s}=\varepsilon_{\sigma, T}^{\prime}-\varepsilon_{\sigma, 20^{\circ} \mathrm{C}}=\varepsilon_{\text {ela }, T}+\varepsilon_{p l a, T}+\varepsilon_{t g}+\varepsilon_{t t c}$ & Diederichs [28], \\
(LITS) & Khoury and Terro [21,22] \\
\hline Semi-implicit & $\varepsilon_{t o t}=\varepsilon_{t t c}^{\prime \prime}+\varepsilon_{\text {ela }, T}+\varepsilon_{\sigma, 20^{\circ} \mathrm{C}}+\varepsilon_{f t s}$ & \\
2 & $\varepsilon_{t t c}^{\prime \prime}=\varepsilon_{l i t s}-\varepsilon_{\text {ela }, T}=\varepsilon_{p l a, T}+\varepsilon_{t g}+\varepsilon_{t t c}$ & Gernay and Franssen [24] \\
\hline Semi-implicit & $\varepsilon_{t o t}=\varepsilon_{t t c}^{\prime}+\varepsilon_{p l a, T}+\varepsilon_{\text {ela }, T}+\varepsilon_{\sigma, 20^{\circ} \mathrm{C}}+\varepsilon_{f t s}$ & Schneider [25], \\
3 & $\varepsilon_{t t c}^{\prime}=\varepsilon_{t t c}^{\prime \prime}-\varepsilon_{p l a, T}=\varepsilon_{t g}+\varepsilon_{t t c}$ & Anderberg and Thelandersson [1] \\
\hline
\end{tabular}

In contrast to the implicit models, the mechanical strain and TTC are formulated separately in explicit models, which represent the real physical meaning of TTC. However, many existing models are neither implicit nor completely explicit, but are semi-implicit. These semi-implicit models can be divided into three types (see Table 1). The first type does not separate TTC from the variation of mechanical strain with temperature and it defines the sum of them as LITS (load induced thermal strain $\varepsilon_{\text {lits }}$ ). For example, Nielsen [27] proposed a linear model for the development of LITS. 
Diederichs [28] presented a nonlinear model for the calculation of LITS as follows,

$$
\varepsilon_{t t c}=\frac{\sigma}{\sigma_{c, 20}}\left(4.12 \times 10^{-5}\left(T-T_{0}\right)-1.72 \times 10^{-7}\left(T-T_{0}\right)^{2}+3.3 \times 10^{-10}\left(T-T_{0}\right)^{3}\right)
$$

where $T_{0}$ is the ambient temperature, $\sigma_{c, 20}$ is the peak stress at ambient temperature. A similar model was also developed by Khoury [21,22] as follows,

$$
\varepsilon_{\text {lits }, 0.3}=-4.39 \times 10^{-5}+2.73 \times 10^{-6} T+6.35 \times 10^{-8} T^{2}-2.19 \times 10^{-10} T^{3}+2.77 \times 10^{-13} T^{4}
$$

The second type can be considered as an improvement of the first one by separating the variation of elastic strain with temperature. For example, Gernay and Franssen formulated TTC individually on the basis of EC2 and ENV [26,29],

$$
\varepsilon_{t t c}^{\prime \prime}=\frac{\sigma}{E_{E C 2}^{\text {implicit }}}-\frac{\sigma}{E_{E N V}}=\frac{2}{3} \frac{\varepsilon_{c, E C 2}-\varepsilon_{c, \min }}{\sigma_{c, T} / \sigma_{c, 20}} \frac{\sigma}{\sigma_{c, 20}}
$$

where $E_{E C 2}^{\text {implicit }}$ and $E_{E N V}$ are the initial tangent modulus of stress-strain curve at temperature T deduced from EC2 and ENV respectively, $\varepsilon_{c, E C 2}$ is the strain at peak stress at temperature $\mathrm{T}$, and $\varepsilon_{c, \min }$ is the minimum strain at peak stress at temperature $\mathrm{T}$.

The third type includes the models proposed by Schneider [25] and Anderberg [1]. In the former [25] $\varepsilon_{\text {pla,T }}$ was formulated explicitly away from $\varepsilon_{t t c}^{\prime}$, but $\varepsilon_{p l a, T}$ is neglected for the pre-load level less than 0.5 . According to the empirical boundary limit imposed by Schneider, TTC is calculated based on the stress ratio as follows, when $\sigma / \sigma_{c, 20} \leq 0.3$ :

$$
\varepsilon_{t c c}^{\prime}=\frac{\sigma}{E_{T}}\left(\frac{\sigma \times(T-20)}{100 \sigma_{c, 20}+\sigma \times(T-20)}+C_{1} \tanh \left[\frac{(0.3 w+2.2)(T-20)}{1000}\right]+C_{2} \tanh \left[\gamma_{0} \times\left(T-T_{g}\right)\right]+C_{3}\right)
$$

when $\sigma / \sigma_{c, 20}>0.3$ :

$$
\varepsilon_{t c c}^{\prime}=\frac{\sigma}{E_{T}}\left(\frac{T-20}{T-313.3}+C_{1} \tanh \left[\frac{(0.3 w+2.2)(T-20)}{1000}\right]+C_{2} \tanh \left[\gamma_{0} \times\left(T-T_{g}\right)\right]+C_{3}\right)
$$

where $E_{T}$ is the elastic modulus at temperature T, $w$ is the moisture content in \%, 
$C_{1}, C_{2}, C_{3}, \gamma_{0}, T_{g}$ are the parameters for calibration. In the latter [1] the TTC is expressed as the function of free thermal strain and applied stress directly as follows,

$$
\left\{\begin{array}{l}
\varepsilon_{t t c}^{\prime}=k \frac{\sigma}{\sigma_{c, 20}} \varepsilon_{f t s} \quad, 20 \leq T \leq 550 \\
\frac{\partial \varepsilon_{t t c}^{\prime}}{\partial T}=0.0001 \frac{\sigma}{\sigma_{c, 20}}, 550 \leq T \leq 800
\end{array}\right.
$$

where $k=2.35$ is a material parameter used for experimental data fitting. This formula is simple and clear but it cannot take into account the effect of plastic strain caused by temperature gradient, which means that it is not completely explicit too.

\subsection{Significance of the research}

According to the analysis described above, the difference among the existing models is the way in which how the strain components are split, while their common problem is that part of the mechanical strain $\varepsilon_{\sigma, T}$, at least the $\varepsilon_{p l a, t g}$ caused by temperature gradient, is implicitly included in TTC. Note that no matter how TTC is defined and what method is adopted for calculating it, the final target is the same, which is to formulate the extra strain caused by different historical loading and heating paths, while the implicit or semi-implicit inclusion of mechanical strain in existing TTC models makes it incapable of capturing this difference precisely $[24,30]$. It should be emphasized here that the incomplete separation between mechanical strain and TTC does not affect the calculation of total strain developed in transient state tests since it is only the difference of division method for constituents. However, the separation of mechanical strain from TTC could help our understanding on the evolution of concrete transient strain and the development of stress-stain-temperature constitutive equations for concrete materials at elevated temperatures. 


\section{Development of explicit model}

\subsection{Description}

The purpose for developing a numerical model is to extract TTC from experimental data and then decompose it into the strain components defined in the transient state test, that is,

$$
\varepsilon_{t t c}=\varepsilon_{\text {tot }}-\left(\varepsilon_{f t s}+\varepsilon_{\sigma, 20^{\circ} \mathrm{C}}+\varepsilon_{\text {ela }, T}+\varepsilon_{\text {pla }, T}+\varepsilon_{t g}\right)
$$

where $\varepsilon_{\text {tot }}$ is the total strain, which is determined experimentally. Thus, the requirement for the simulation is to calculate the other strain components on the right hand side of Eq.(10). Capturing the evolution of these strain components at elevated temperatures is necessary for investigating the influence of including them in TTC. A significant difference of this model from existing models is that the effect of temperature gradient on the development of mechanical strain is considered, while it is always neglected in previous studies.

Under the action of thermal gradient in a transient state test, the expansion of concrete is always larger in the region near the exposed surface than that near the center, which leads stress shifting from inside to outside (see Fig.2a). The deterioration of mechanical properties is much fast in the region near the exposed surface than that near the center, which makes stress transfer in an opposite direction to balance the deformation (see Fig.2b). The combination of these two actions results in a stress fluctuation, which can produces a transient mechanical stress gradient that could be much stronger than thermal stress gradient. This mechanical stress gradient can influence not only the temperature of crush point but also the magnitude of measured strains since there will be some residual strain yielded from the unloading process of stress fluctuation. 


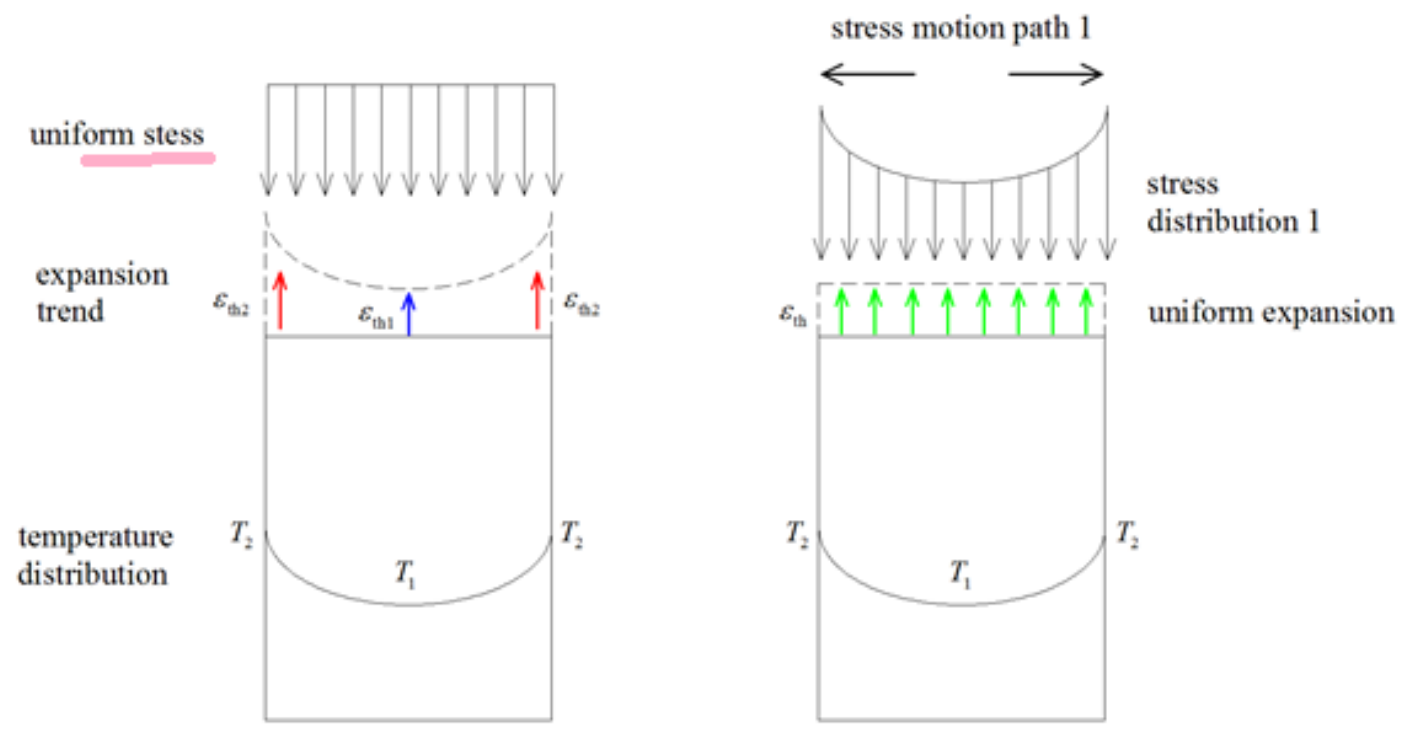

a. Stress resulted from thermal expansion gradient

[can you replot Fig.2a. Also make sure first letter be capital in Fig1a and 1b]

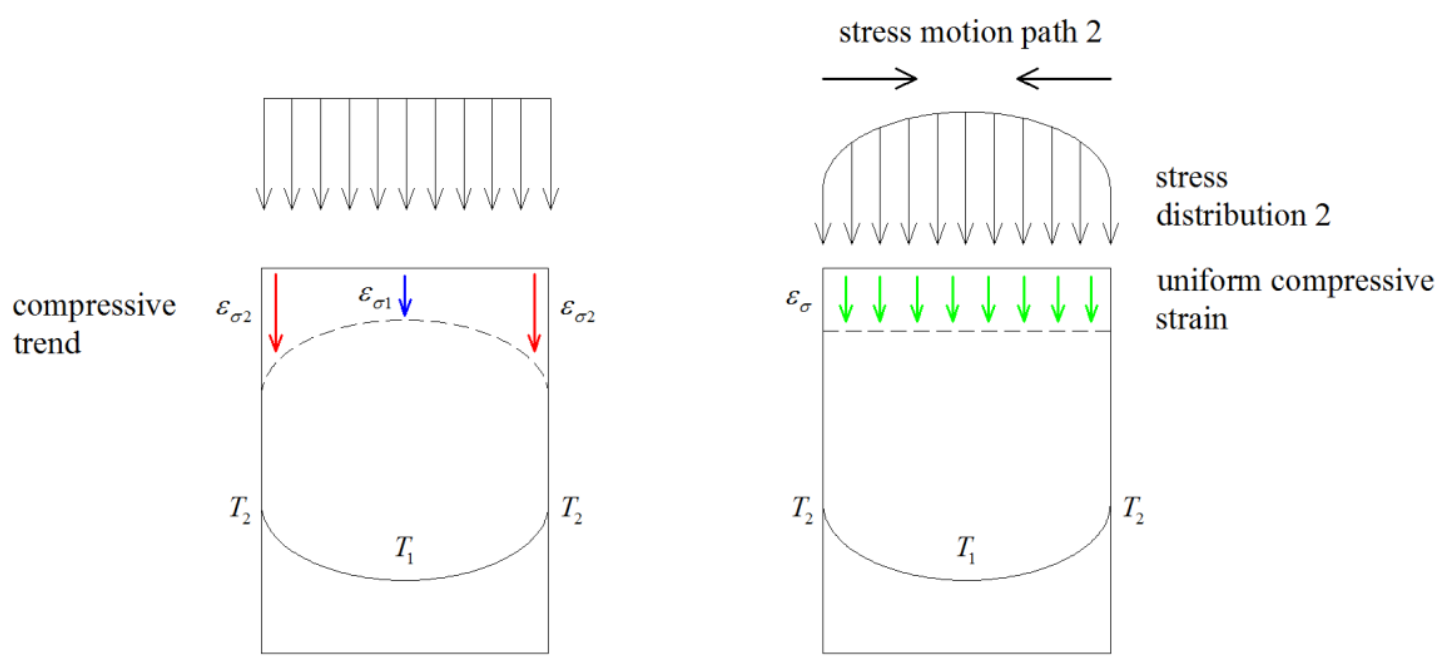

b. Stress resulted from mechanical strain gradient

Fig.2 Stress redistribution under thermal gradient.

In order to simulate the above process, two rigid steel plates are employed to interact with the concrete cylinder specimen (see Fig.3). In this way, the applied stress 
distribution on the top surface can fluctuate with temperature instantly while the total external load remains constant. In addition, the following assumptions are used in the present model:

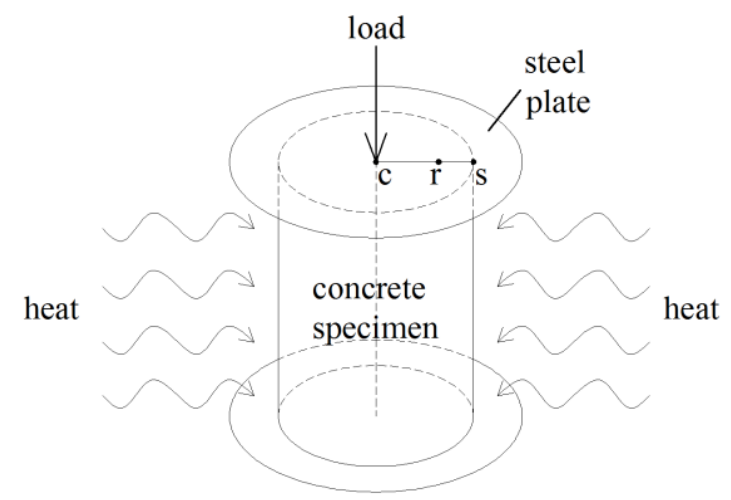

Fig.3 Graphical representation of present numerical model

(a) The problem is treated as an axial-symmetrical problem with coupled thermal and stress fields.

(b) A free contact surface is used between the rigid steel plates and concrete cylinder specimen.

(c) The displacement boundary conditions of the concrete cylinder specimen are applied at the central axis where the horizontal displacement is zero and at the bottom surface where the vertical displacement is zero.

(d) The key parameters used to define the stress-strain relations, like peak stress, strain at peak stress and elastic modulus are obtained from corresponding steady state tests, which exclude the effect of TTC.

(e) The curvatures of normalized stress-strain functions vary with temperature rather than being fixed as in many previous models $[1,26,31,32]$. This is because the curvature of a normalized stress-strain function can influence the calculation of plastic strain at high temperature, which will be illustrated in Sec.3.3. 
(f) The selected stress-strain function must have an inverse form in order to implement the calculation.

(g) Three points, c, r, and s represent the center point, reference point ( 0.7 times of radius) and surface point, which are selected to inspect the variation of thermal and mechanical responses (see Fig.3).

\subsection{Calculation of temperature field}

The first step of the analysis is to calculate the transient temperature field $T(x, y, \mathrm{z}, t)$, which describes the temperature at each point in concrete at time $t$. In the transient state test, there is no internal heat generated in the concrete, thus, the following heat transfer equation can be used,

$$
\frac{\partial T}{\partial t}=\frac{\lambda}{\rho c} \times\left(\frac{\partial^{2} T}{\partial x^{2}}+\frac{\partial^{2} T}{\partial y^{2}}+\frac{\partial^{2} T}{\partial z^{2}}\right)
$$

where $\lambda$ is the thermal conductivity in $\mathrm{W} /\left(\mathrm{m}^{\circ} \mathrm{C}\right), \quad \rho$ is the density of the concrete in $\mathrm{kg} / \mathrm{m}^{3}, \mathrm{c}$ is the specific heat in $\mathrm{J} /\left(\mathrm{kg}{ }^{\circ} \mathrm{C}\right), \mathrm{x}, \mathrm{y}$ and $\mathrm{z}$ are the coordinates.

To obtain the temperature distribution, the following initial and boundary conditions are used,

$$
\begin{gathered}
T(x, y, \mathrm{z}, 0)=T_{0} \\
\lambda \times\left(\frac{\partial T}{\partial x} l_{x}+\frac{\partial T}{\partial y} l_{y}+\frac{\partial T}{\partial z} l_{z}\right)=0 \\
\lambda \times\left(\frac{\partial T}{\partial x} l_{x}+\frac{\partial T}{\partial y} l_{y}+\frac{\partial T}{\partial z} l_{z}\right)=h \times\left(T_{g}-T_{s}\right)+e \times S \times\left(T_{g}^{4}-T_{s}^{4}\right)
\end{gathered}
$$

where $T_{0}=20^{\circ} \mathrm{C}$ is the ambient temperature, $1_{\mathrm{x}}, \mathrm{l}_{\mathrm{y}}$, and $\mathrm{l}_{\mathrm{z}}$ are the direction cosines of the normal to the boundary surface, $\mathrm{h}$ is the convection coefficient in $\mathrm{W} /\left(\mathrm{m}^{2}{ }^{\circ} \mathrm{C}\right), e$ is the resultant emissivity of the exposure surface, $S=5.67 \times 10^{-8} \mathrm{~W} /\left(\mathrm{m}^{2}{ }^{\circ} \mathrm{C}^{4}\right)$ is the 
Stefan-Boltzmann constant, $T_{S}$ is the surface temperature of concrete and $T_{g}$ is the environment gas temperature determined based on the heating rate. Eq.(13) is applied to the top, bottom, and central lines, whereas Eq.(14) is applied to the exposed line. Eqs.(11)-(14) are solved using the commercial software ABQUAS.

\subsection{Constitutive laws for thermal-mechanical analysis}

It is well-known that the stress-strain relation of concrete at ambient temperature is nonlinear and has a curvature. When it is applied to elevated temperatures it is often to assume this curvature remains unchanged; that is only the stress and strain at the peak point of the stress-strain curve that change with temperature. Fig.4 shows the comparison of the stress-strain relations at different temperatures after they have been normalized by using their peak point values, in which the dash lines are from the experimental studies of Anderberg [1] and the solid lines are calculated by using three different theoretical models [1,26,31] that have been adopted widely. It is evident from the figure that the curvatures of experimentally obtained stress-strain relations vary with temperature; whereas the theoretical models do not give this phenomenon because they use constant curvature. This is an important characteristic but is frequently ignored. To overcome this drawback, herein we use the model proposed by Khennane [33] to include the change of curvature with temperature,

$$
\left(\frac{\sigma-r \times \sigma_{c, T}}{\sigma_{c, T}-r \times \sigma_{c, T}}\right)^{2}+\left(1+\frac{\varepsilon_{p, T} E_{T}}{\varepsilon_{c, T} E_{T}-\sigma_{c, T}}\right)^{2}=1
$$

where $\sigma$ is the applied stress, $\mathrm{r}$ is the yield stress ratio, and $\varepsilon_{p, T}$ is the plastic strain. 


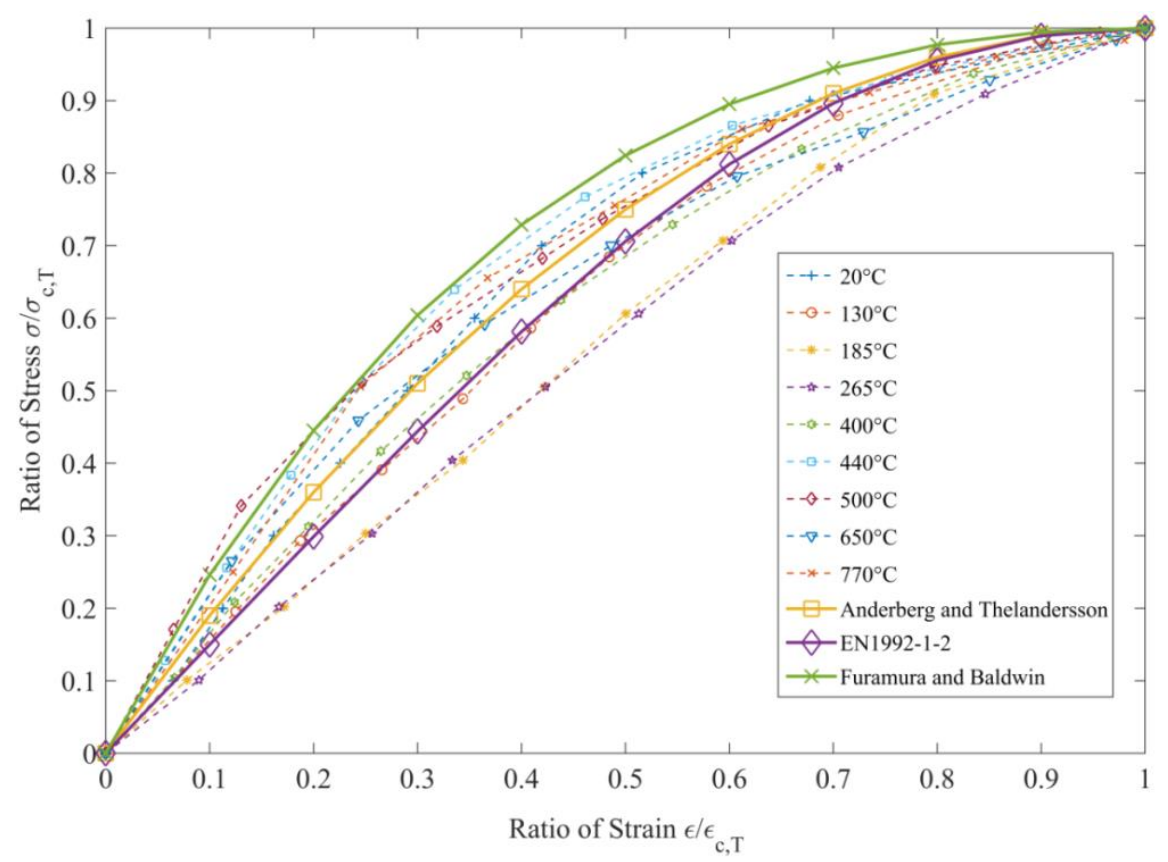

Fig.4 Variation of stress-strain curvatures with temperature (data from $[1,26,31,33]$ ).

\subsection{Thermal-mechanical analysis}

The key of the thermal-mechanical analysis is to quantify the effect of temperature gradient and related stress fluctuation on the development of mechanical strain in the transient state test. Fig.5 illustrates the concept of the analysis. Under thermal gradient, the initially uniform stress $\sigma_{0}$ will fluctuate as the direction of blue arrows to eliminate the mechanical strain gradient caused by the change of constitutive relations. Thus, the balanced strain will be $\varepsilon_{1}$, which is between $\varepsilon_{0, \mathrm{C}}$ (strain evaluated according to the temperature at center) and $\varepsilon_{0, \mathrm{~S}}$ (strain evaluated according to the temperature at surface) as shown in Fig.5. In addition, if there is an unloading at a stress higher than the yield stress, irrecoverable residual strain $\varepsilon_{r, T}$ is produced. In this way, the fluctuation will be amplified further as indicated by the red arrows in the figure and the balanced strain will have a higher value $\varepsilon_{2}$. Meanwhile, the opposite stress fluctuation caused by thermal strain gradient can produce plastic strain, which will influence the balance point. This indicates that to estimate the variation of mechanical strain only based on the temperature of a single point, disregarding its location, is 
inappropriate since there is an extra mechanical strain component $\varepsilon_{p l a, t g}$ yielded by the temperature gradient in the transient state test. The way to implement above-mentioned idea into the numerical analysis is described as follows.

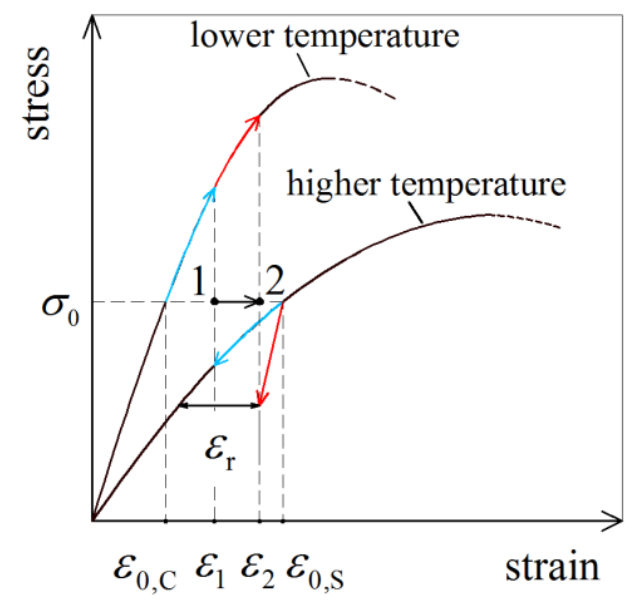

Fig.5 Rebalance of mechanical strain under thermal gradient

The aim of the numerical model developed here is to calculate the strain:

$$
\varepsilon_{s, \exp }=\varepsilon_{f t s}+\varepsilon_{\sigma, T}
$$

where $\varepsilon_{\sigma, T}$ is defined by Eq.(1). To implement the numerical calculation, $\varepsilon_{\sigma, T}$ is rewritten as:

$$
\varepsilon_{\sigma, T}=\varepsilon_{e, T}+\varepsilon_{p, T}+\varepsilon_{r, T}
$$

where $\varepsilon_{e, T}$ and $\varepsilon_{p, T}$ are the elastic and plastic strains at temperature T, respectively. According to the stress-strain relation shown in Sec.3.3, for one point at any location on the top surface of the concrete cylinder specimen, their value at the increment time step i can be expressed as follows,

$$
\begin{gathered}
\varepsilon_{e, T}^{i}=\frac{\sigma_{i}}{E_{T}\left(T_{i}\right)} \\
\varepsilon_{p, T}^{i}=\left(\varepsilon_{c, T}\left(T_{i}\right)-\frac{\sigma_{c, T}\left(T_{i}\right)}{E_{T}\left(T_{i}\right)}\right)\left(1-\sqrt{1-\left(\frac{\sigma_{i}-r \sigma_{c, T}\left(T_{i}\right)}{r \sigma_{c, T}\left(T_{i}\right)-r \sigma_{c, T}\left(T_{i}\right)}\right)^{2}}\right)
\end{gathered}
$$

where $\sigma_{i}, T_{i}$ are the stress and temperature at that point at time increment i, $E_{T}(T)$ 
is the elastic modulus, $\sigma_{c, T}(T)$ is the peak stress, and $\varepsilon_{c, T}(T)$ is the strain at peak stress. $E_{T}(T), \sigma_{c, T}(T)$ and $\varepsilon_{c, T}(T)$ are the functions of temperature T, which can be obtained from corresponding steady state tests. The accumulated residual strain $\varepsilon_{r, T}$ caused by unloading due to stress fluctuation can be calculated using an incremental method as follows,

$$
\Delta \varepsilon_{r, T}^{i}=\left(\varepsilon_{c, T}\left(T_{i}\right)-\frac{\sigma_{c, T}\left(T_{i}\right)}{E_{T}\left(T_{i}\right)}\right)\left(1-\sqrt{1-\left(\frac{f_{r}\left(\sigma_{i}, \sigma_{i-1}\right)-r \sigma_{c, T}\left(T_{i}\right)}{r \sigma_{c, T}\left(T_{i}\right)-r \sigma_{c, T}\left(T_{i}\right)}\right)^{2}}\right)
$$

where $f_{r}\left(\sigma_{i}, \sigma_{i-1}\right)$ is the corresponding increment of unloading stress:

$$
f_{r}\left(\sigma_{i}, \sigma_{i-1}\right)=\left\{\begin{array}{l}
0, \sigma_{i-1}<\sigma_{i} \\
\sigma_{i-1}-\sigma_{i}, \sigma_{i} \leq \sigma_{i-1}
\end{array}\right.
$$

The gradient of free thermal strain induces stress fluctuation but its value only depends on temperature:

$$
\varepsilon_{f t s}^{i}=\alpha\left(T_{i}\right) \times T_{i}
$$

where $\alpha\left(T_{i}\right)$ is the coefficient of thermal expansion in ${ }^{\circ} \mathrm{C}^{-1}$. According to Eqs.(18)(22), all strain components can be calculated. At a time increment i, $\varepsilon_{s, \exp }$ at node $\mathrm{j}$ can be calculated as follows,

$$
\begin{aligned}
\varepsilon_{s, \exp }^{i, j} & =\varepsilon_{f i s}^{i, j}+\varepsilon_{e, T}^{i, j}+\varepsilon_{p, T}^{i, j}+\sum_{i=1}^{i} \Delta \varepsilon_{r, T}^{i, j} \\
& =\alpha\left(T_{i, j}\right) T_{i, j}+\frac{\sigma_{i, j}}{E_{T}\left(T_{i, j}\right)} \\
& +\left(\varepsilon_{c, T}\left(T_{i, j}\right)-\frac{\sigma_{c, T}\left(T_{i, j}\right)}{E_{T}\left(T_{i, j}\right)}\right) \times\left(1-\sqrt{1-\left(\frac{\sigma_{i, j}-r \sigma_{c, T}\left(T_{i, j}\right)}{r \sigma_{c, T}\left(T_{i, j}\right)-r \sigma_{c, T}\left(T_{i, j}\right)}\right)^{2}}\right) \\
& +\sum_{i=1}^{i}\left(\left(\varepsilon_{c, T}\left(T_{i, j}\right)-\frac{\sigma_{c, T}\left(T_{i, j}\right)}{E_{T}\left(T_{i, j}\right)}\right)\left(1-\sqrt{1-\left(\frac{f_{r}\left(\sigma_{i, j}, \sigma_{i-1, j}\right)-r \sigma_{c, T}\left(T_{i, j}\right)}{r \sigma_{c, T}\left(T_{i, j}\right)-r \sigma_{c, T}\left(T_{i, j}\right)}\right)^{2}}\right)\right)
\end{aligned}
$$

Due to the restraint provided by the rigid plates, at time increment $i$, all nodes on the top line should have identical strain, that is 


$$
\varepsilon_{s, \exp }^{i, 1}\left(\sigma_{i, 1}, T_{i, 1}\right)=\varepsilon_{s, \exp }^{i, 2}\left(\sigma_{i, 2}, T_{i, 2}\right)=\ldots=\varepsilon_{s, \exp }^{i, n-1}\left(\sigma_{i, n-1}, T_{i, n-1}\right)=\varepsilon_{s, \exp }^{i, n}\left(\sigma_{i, n}, T_{i, n}\right)
$$

In addition, the force balance requires the following equation:

$$
\sum_{j=1}^{n}\left(\sigma_{i, j} \pi\left(\left(\frac{j \times R}{\mathrm{n}}\right)^{2}-\left(\frac{(j-1) \times R}{\mathrm{n}}\right)^{2}\right)\right)=F_{0}
$$

where $F_{0}$ is the externally applied mechanical load (i.e. pre-load) and $\mathrm{R}$ is the radius of concrete cylinder.

In each time step, the transient temperature field is calculated first according to the thermal analysis described in Sec.3.2 to obtain the nodal temperatures. Then the stress analysis is carried out using Eqs.(24) and (25) to obtain an equilibrium state from which both the stress and strain are obtained for each node. In this way, the relationship between $\varepsilon_{s, \exp }$ and temperature $\mathrm{T}$ can be obtained. For a given heating-loading condition and with the knowledge of specific material properties from the steady state test, TTC can be extracted accurately and explicitly from the total strain measured in the transient state test:

$$
\varepsilon_{\text {ttc }}\left(F_{0}, T\right)=\varepsilon_{\text {tot }}\left(F_{0}, T\right)-\varepsilon_{s, \exp }\left(F_{0}, T\right)
$$

\section{Case Study}

\subsection{Description}

A total of 10 different cases are analyzed according to the experiment of Anderberg [1]. The details for each case are listed in Table 2. Cases 1-3 are designed to validate the numerical model, whereas cases 4-7 are designed to investigate the effect of temperature gradient and different methods used on calculating TTC from the total strain measured in the transient state test. Cases $6,8-10$ are the parametric study of heating rate used in transient tests to explore the sensitivity of the results to thermal gradient. All the specimens discussed here are the axially unrestrained cylinders with 
$75 \mathrm{~mm}$ diameter and $150 \mathrm{~mm}$ height.

Table 2. Case study details

\begin{tabular}{|c|c|c|c|c|}
\hline Category & Loading regime & Case & Temperature & Load \\
\hline \multirow{2}{*}{ Steady } & \multirow[t]{2}{*}{ Load, Temp } & 1 & $20^{\circ} \mathrm{C}$ & $191 \mathrm{kN}$ \\
\hline & & 2 & $500{ }^{\circ} \mathrm{C}$ & $109 \mathrm{kN}$ \\
\hline \multirow{9}{*}{ Transient } & \multirow{9}{*}{ Load, Temp } & Case & Heating Rate & Load level \\
\hline & & 3 & \multirow{5}{*}{$5{ }^{\circ} \mathrm{C} / \mathrm{min}$} & $0 \%$ \\
\hline & & 4 & & $22.5 \%$ \\
\hline & & 5 & & $35 \%$ \\
\hline & & 6 & & $45 \%$ \\
\hline & & 7 & & $67.5 \%$ \\
\hline & & 8 & $1{ }^{\circ} \mathrm{C} / \mathrm{min}$ & \multirow{3}{*}{$45 \%$} \\
\hline & & 9 & $10^{\circ} \mathrm{C} / \mathrm{min}$ & \\
\hline & & 10 & $20^{\circ} \mathrm{C} / \mathrm{min}$ & \\
\hline
\end{tabular}

\subsection{Identification of material properties}

The numerical analysis requires the input of two sets of parameters, namely thermal properties and mechanical properties. In the heat transfer analysis, a time-dependent temperature curve is used for the environment gas temperature which is applied to the exposed surface. The thermal properties required include the thermal conductivity, specific heat, and thermal expansion; all are assumed to be temperature-dependent and taken from the experimental study of Anderberg [1]. In addition, a convection heat transfer coefficient of $25 \mathrm{~W} /\left(\mathrm{m}^{2}{ }^{\circ} \mathrm{C}\right)$ and a resultant emissivity factor of 0.7 are used for the surface film condition and radiative heat transfer.

In the thermal-mechanical analysis, the mechanical properties required include the 
density, elastic modulus, Poisson's ratio, peak stress, strain at peak stress and crush strain. There are very few experimental results on the effect of temperature on Poisson's ratio and crush strain $[34,36]$. Therefore, in the present numerical examples the Poisson's ratio is assumed to be 0.15 and the crush strain is assumed to be a function of temperature and increases linearly from the value of 0.005 at ambient temperature to 0.013 at $800{ }^{\circ} \mathrm{C}$. The values of the peak stress, strain at peak stress and elastic modulus are taken from Anderberg's study [1] as follows,

$$
\begin{gathered}
\sigma_{c, T}(T)=\left\{\begin{array}{l}
\sigma_{c, 20} \times(1-0.0001 T) \\
\sigma_{c, 20} \times(0.96-0.0023(T-400)), 400<T \leq 600 \\
\sigma_{c, 20} \times(0.5-0.00135(T-600)), 600<T \leq 800
\end{array}\right. \\
\varepsilon_{c, T}(T)=\left\{\begin{array}{lr}
3 \quad, 20<T \leq 200 \\
\frac{T-200}{90}+3,200<T \leq 600 \\
8 \quad, 600<T \leq 800
\end{array}\right. \\
E_{T}(T)=E_{20} \times(-0.0012 T+1.0244), 20<T \leq 800
\end{gathered}
$$

where $\sigma_{c, 20}=43.8 \mathrm{MPa}$ and $E_{20}=28 \mathrm{GPa}$ are the compressive strength and elastic modulus of concrete at $20{ }^{\circ} \mathrm{C}$. Based on the mechanical properties defined above and the constitutive equation in Sec.3.3, the stress-strain curves at various temperatures are plotted in Fig. 6. 


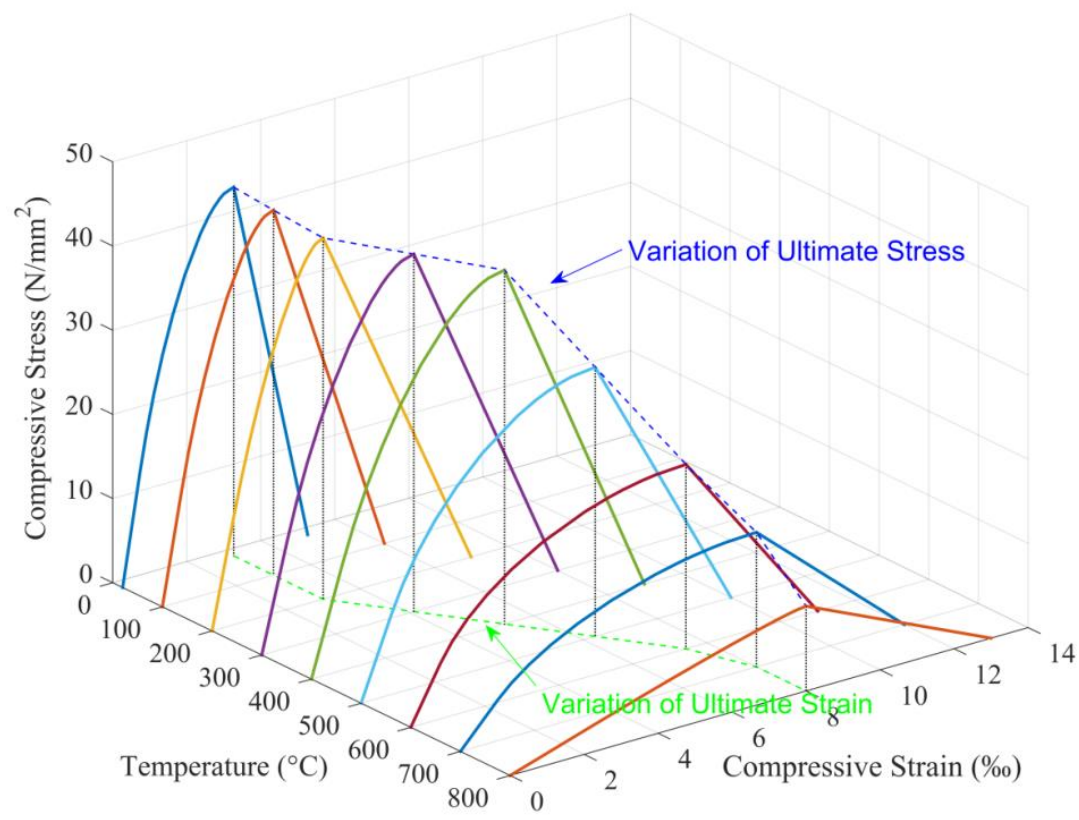

Fig.6 Constitutive model formulated in numerical calculation (data from [1]).

\section{Model Validation}

\subsection{Validation of thermal analysis}

In Anderberg's experiment, the specimen was first heated to $800^{\circ} \mathrm{C}$ in a rate of $5^{\circ} \mathrm{C} / \mathrm{min}$, and then the temperature was maintained for $1.5 \mathrm{~h}$. Three thermocouples were installed at three points as depicted in Fig.3 to monitor the variation of temperatures there. As it is demonstrated in Fig.7, the results given by the present numerical model and experiment are very close at the central and reference points. However, at the surface the temperature computed from the present numerical model is slightly lower than the experimental value until the temperature almost reaches its maximum value. The reason for this is because the experimentally measured temperature is the gas temperature at the exposed surface, whereas the numerically predicted temperature is the surface temperature of concrete. The difference between them represents the interface effect of the heat transfer between different phases. It is observed from the figure that the experimentally measured surface temperature is very close to the heating rate, i.e. the 
temperature of the furnace rather than the surface temperature of concrete. Nevertheless, the difference between them is small and its effect is insignificant particularly for the temperature greater than $400{ }^{\circ} \mathrm{C}$ when concrete deteriorates sharply.

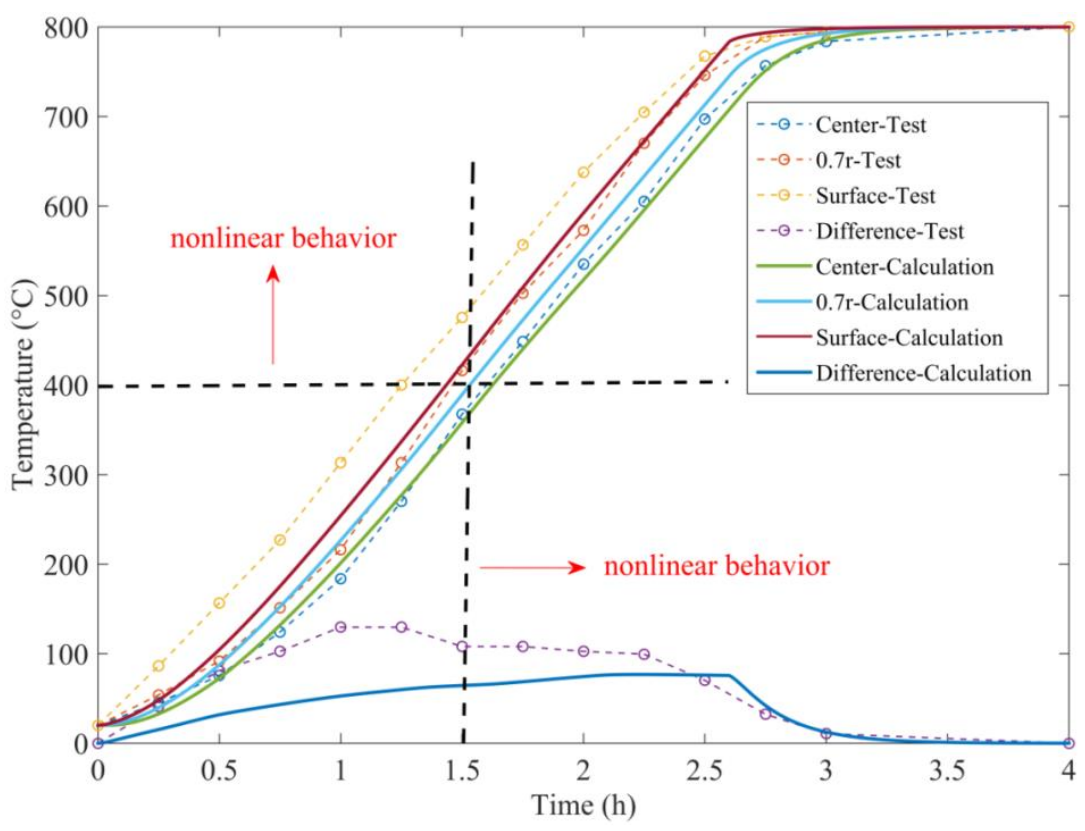

Fig.7 Validation of thermal response in transient state test

\subsection{Validation of thermal-mechanical analysis}

\subsubsection{Free thermal strain}

Case 3 with $0 \%$ pre-fire load level is designed to simulate the free thermal strain in the transient state test. The corresponding experimental data and predicted value are plotted in Fig.8. It can be seen from the figure that there is excellent agreement between the numerical and experimental results. This demonstrates the capability of the present model in capturing the response of thermal expansion in the transient state test. 


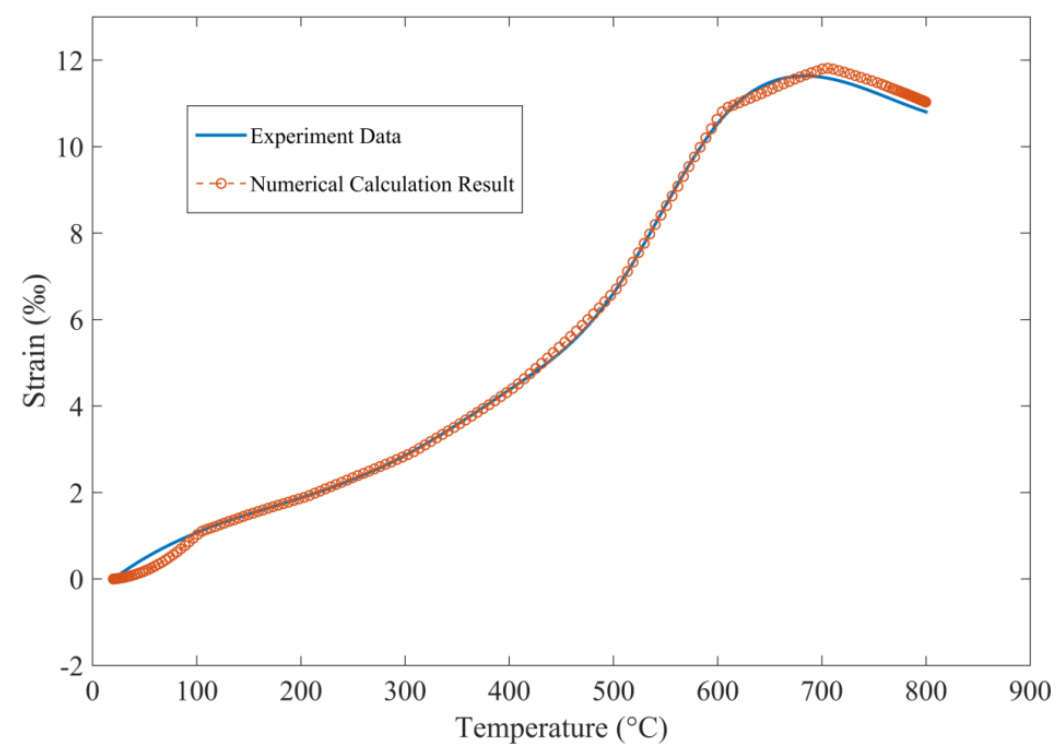

Fig. 8 Validation of free thermal strain in transient state test (case 3)

\subsubsection{Mechanical strain}

In order to validate the appropriateness of the selected constitutive model, the stressstrain curves calculated by using Anderberg's model [1] and Khennane model [33] are plotted in Fig.9. Compared with Anderberg's model, the use of Khennane model gives a slight better fit to the experimental curves. This indicates that the use of Khennane model can accurately simulate the mechanical strain in the transient state test, especially when the variation of curvatures needs to take in account, as discussed in Sec.3.3.

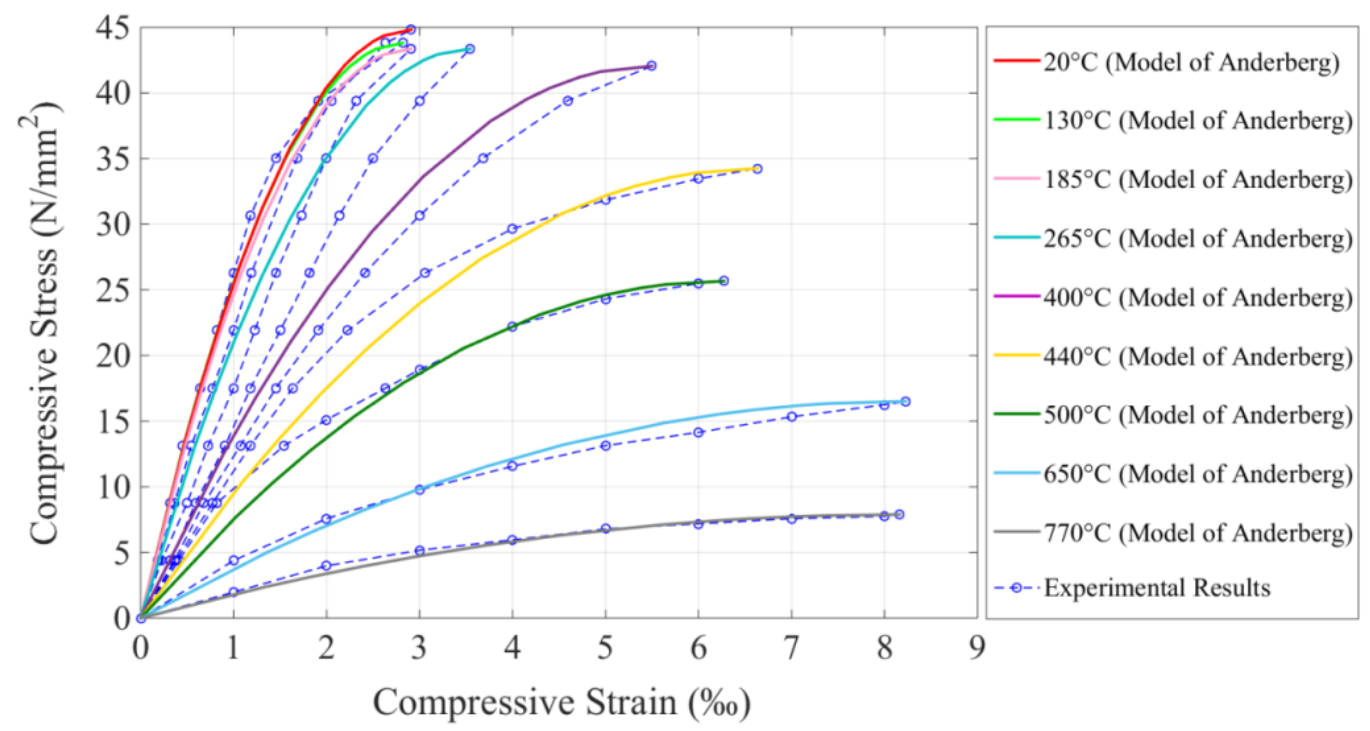


a. Comparison of Anderberg's original model and experimental results

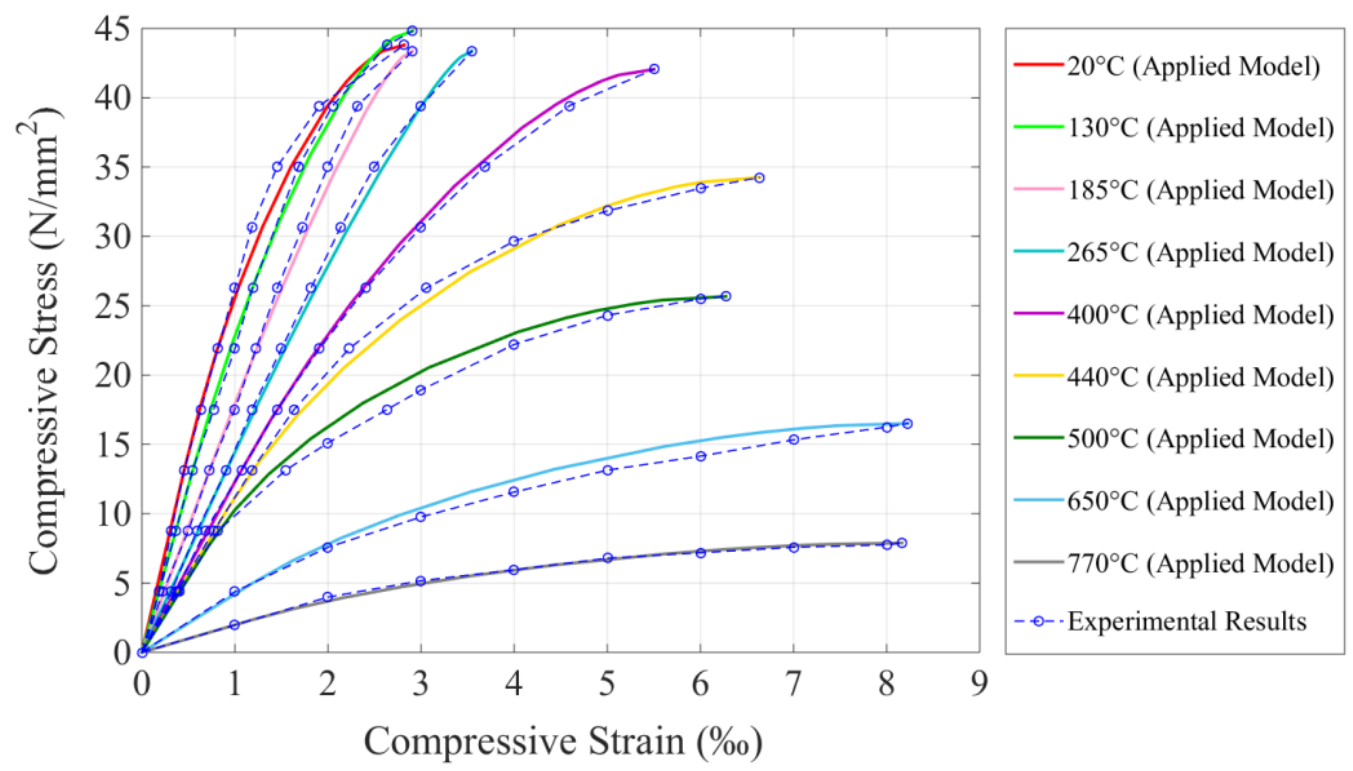

b. Comparison of the applied model and experimental results.

Fig.9 Validation of the accuracy of applied theoretical model

Cases 1 and 2 are designed to validate the accuracy of the numerical model. For the ambient temperature and a high temperature $\left(500{ }^{\circ} \mathrm{C}\right)$, the numerical model is run for both loading and unloading. The corresponding results are shown in Fig.10. It can be seen from the figure that the numerical results match perfectly with the theoretical predictions for both the loading and unloading situations. 


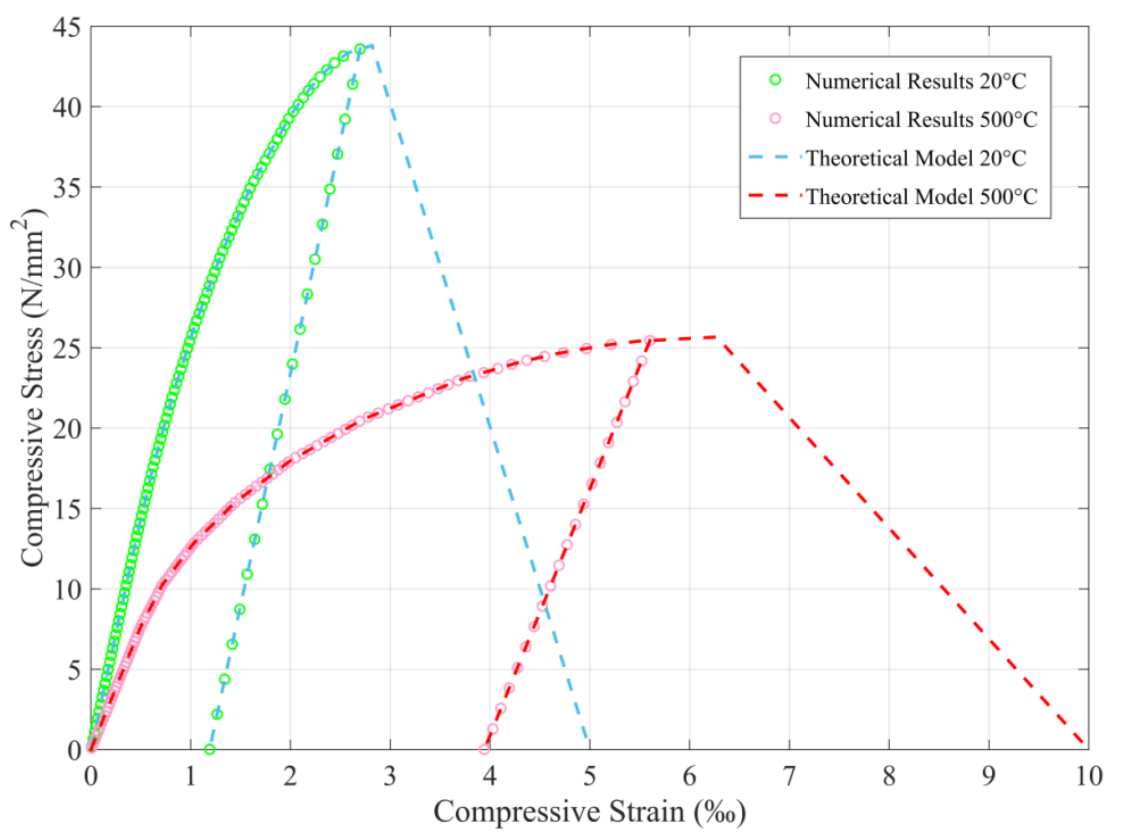

Fig.10 Validation of the numerical implementation for theoretical models (cases 1 and 2)

\section{Results and discussions}

\subsection{Effect of thermal gradient on applied stress fluctuation in transient state test}

To illustrate the effect of temperature gradient on stress fluctuation, the variations of axial compressive stresses on the top of concrete cylinder with time obtained in cases 4 and 7 are plotted in Fig.11b as a function of time for each of the 21 analysis points shown in Fig.11a.

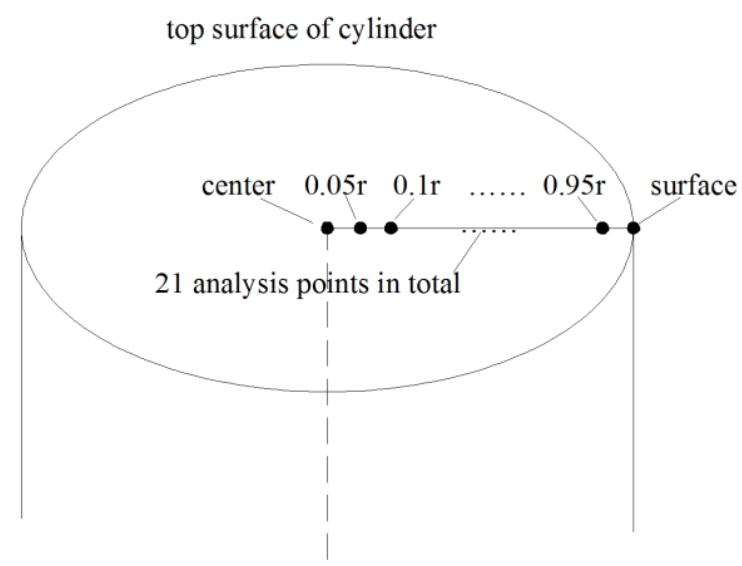




\section{a. Analysis points}

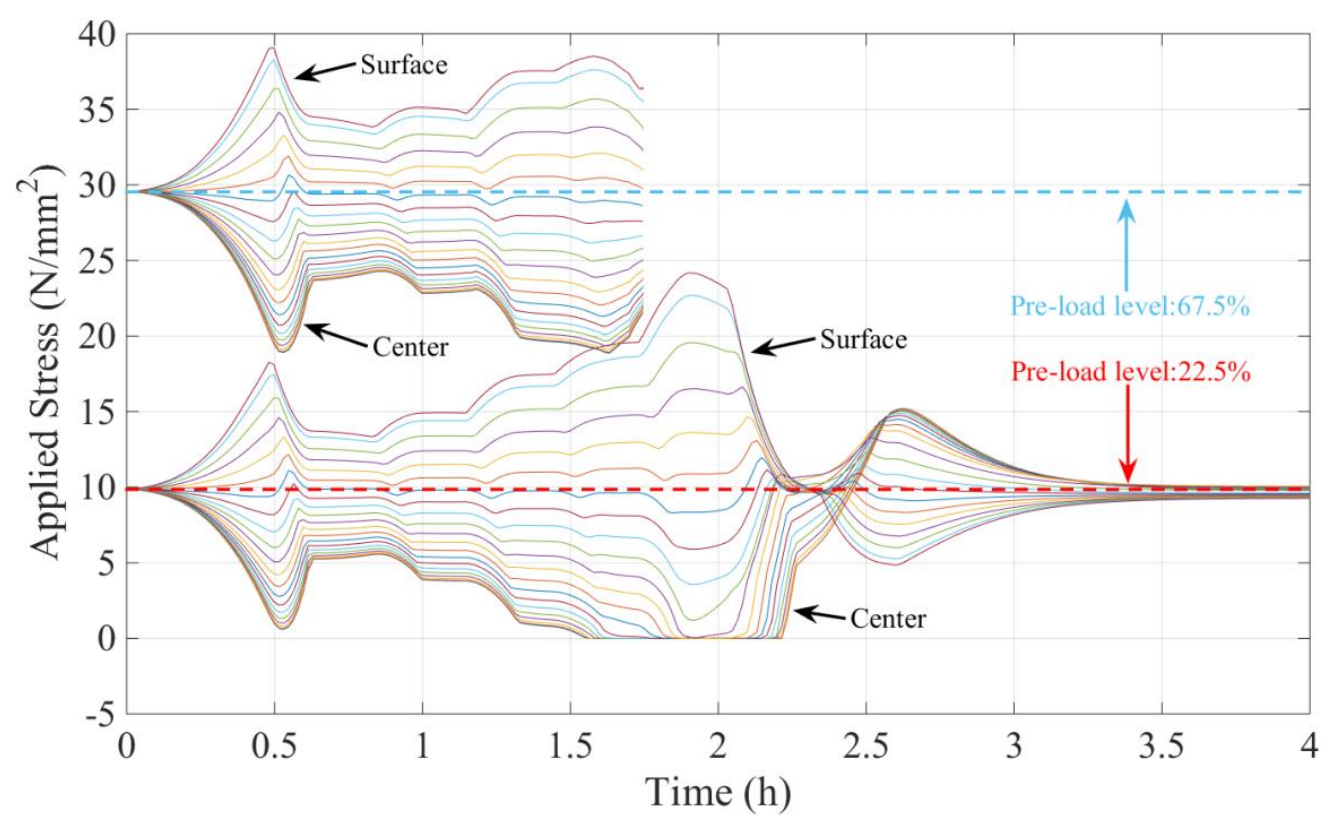

b. Stress fluctuations with time (case 4 and case 7 )

Fig.11 Stress fluctuations resulting from thermal gradient in transient test

For case 4 (load level $22.5 \%$, heating rate $\left.5{ }^{\circ} \mathrm{C} / \mathrm{min}\right)$, when compared with the dash line representing constant pre-stress, the predicted stresses using the present model (solid lines) show a strong fluctuation from the beginning until the latest stage of fire exposure where the temperature gradient decreases to 0 . The compressive stress on the surface increases sharply at the beginning because of emergent temperature gradient. With the increase of temperature and stress gradient, mechanical strain gradient develops in the opposite direction, which confines the further development of the stress fluctuation from center to exposed surface and thus leads to the slight reverse trend at around 0.5 h. However, due to the mild deterioration of mechanical properties at early stage, the overall trend before $500{ }^{\circ} \mathrm{C}$ is the relocation of stress from center to surface. After $500{ }^{\circ} \mathrm{C}$ (around $2 \mathrm{~h}$ of fire exposure), the mechanical properties of concrete begin to deteriorate quickly. Thus the fluctuation trend turns in an opposite direction. Until around $2.5 \mathrm{~h}$, after temperature approaches around $700{ }^{\circ} \mathrm{C}$, the stress distribution is totally opposite. In the last $1.5 \mathrm{~h}(2.5-5 \mathrm{~h})$, the heating rate becomes zero and there is 
no temperature difference. In this case the stress gradient caused by thermal gradient becomes minimum. Finally, it ends up with almost an even stress distribution as the start and the slight difference is caused by evolution of different residual strains accumulated at different points. Although the specimen has no damage during the whole process due to relatively low pre-fire load level, strong stress fluctuation is obviously observed, in which the highest stress could be twice more than the initial value while the lowest stress could be zero.

For case 7 (load level $67.5 \%)$, the basic trend in the early stage $(0-1.5 \mathrm{~h})$ is very similar to that shown in case $4(22.5 \%$ load level $)$. This demonstrates that before $400{ }^{\circ} \mathrm{C}$, the stress fluctuation is controlled mainly by the thermal expansion. After $1.5 \mathrm{~h}$, when temperature hits to $400{ }^{\circ} \mathrm{C}$, however, the reverse convergence happens much earlier than that happened in the case 4 . This is probably attributed to the large mechanical strain due to the application of high pre-fire load. The sharp deterioration in mechanical properties and the accumulated irrecoverable plastic strain are considerably amplified by the high pre-fire load. Before $2 \mathrm{~h}$ and just after the distribution trend turns around, the curves terminate. This is because the specimen is crushed due to the stress at one point reaches to its compressive strength. This indicates that the stress fluctuation may also influence the temperature of crush point. In conclusion, the stress fluctuation caused by temperature gradient in transient state test is complicated and it is too large to be ignored. The predicted mechanical strain, without considering the effect of temperature gradient, is significantly underestimated particularly when the temperature is high.

\subsection{Effect of thermal gradient on calculating TTC in transient test}

To quantify the effect of temperature gradient on the TTC obtained from a transient state test, the development of different strain components at the reference point in cases 
4-7 is plotted in Fig.12 as a function of temperature, in which the free thermal strain $\varepsilon_{f t s}$ and the total strain $\varepsilon_{\text {tot }}$ are taken from the experimental results of Anderberg [1]. The difference between them is the sum of the mechanical strain and TTC. The four dash lines shown in Fig.12 represent the strains when the free thermal strain is added by different parts of mechanical strain, which are calculated by using the semi-implicit models 1-3 as discussed in Sec.2.2 and our proposed explicit numerical model described in Sec.3, respectively. The difference between the total measured strain and any of the calculated curves is regarded as LITS or TTC according to different authors (see Fig.12b), as discussed in Sec.2.2. Fig.12c illustrates the various parts of mechanical strain. The strain definitions used in Fig.12b and Fig.12c can be applied to other cases.

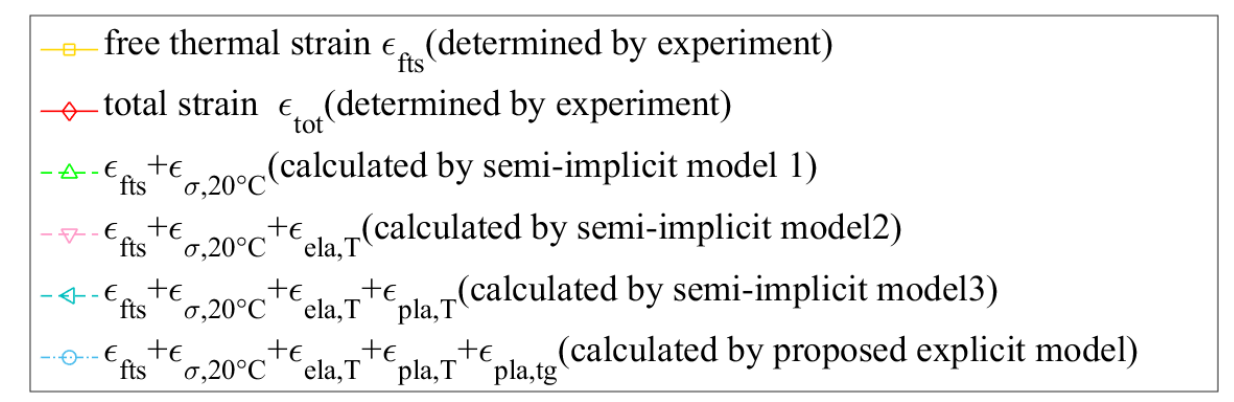

a. Legend for all

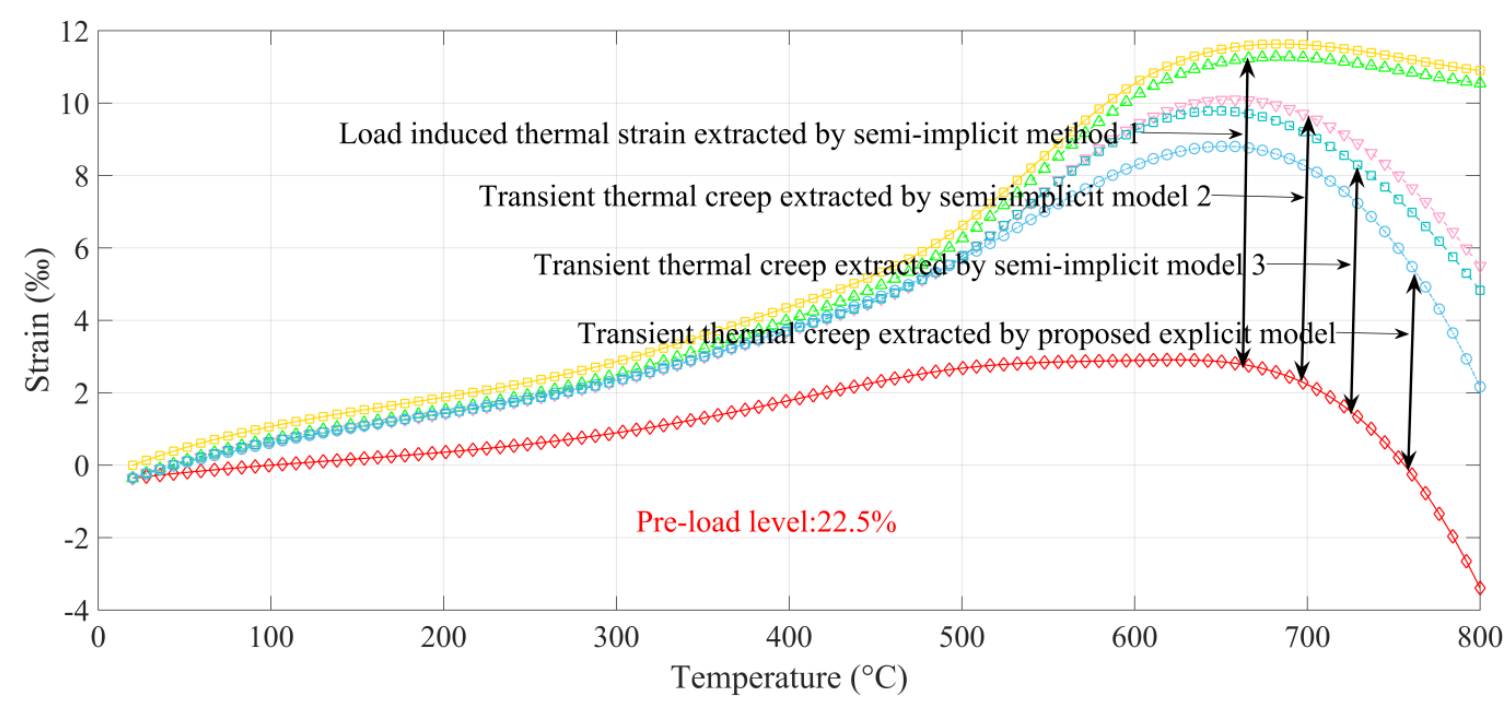




\section{b. Loadlevel-22.5\% (case 4)}

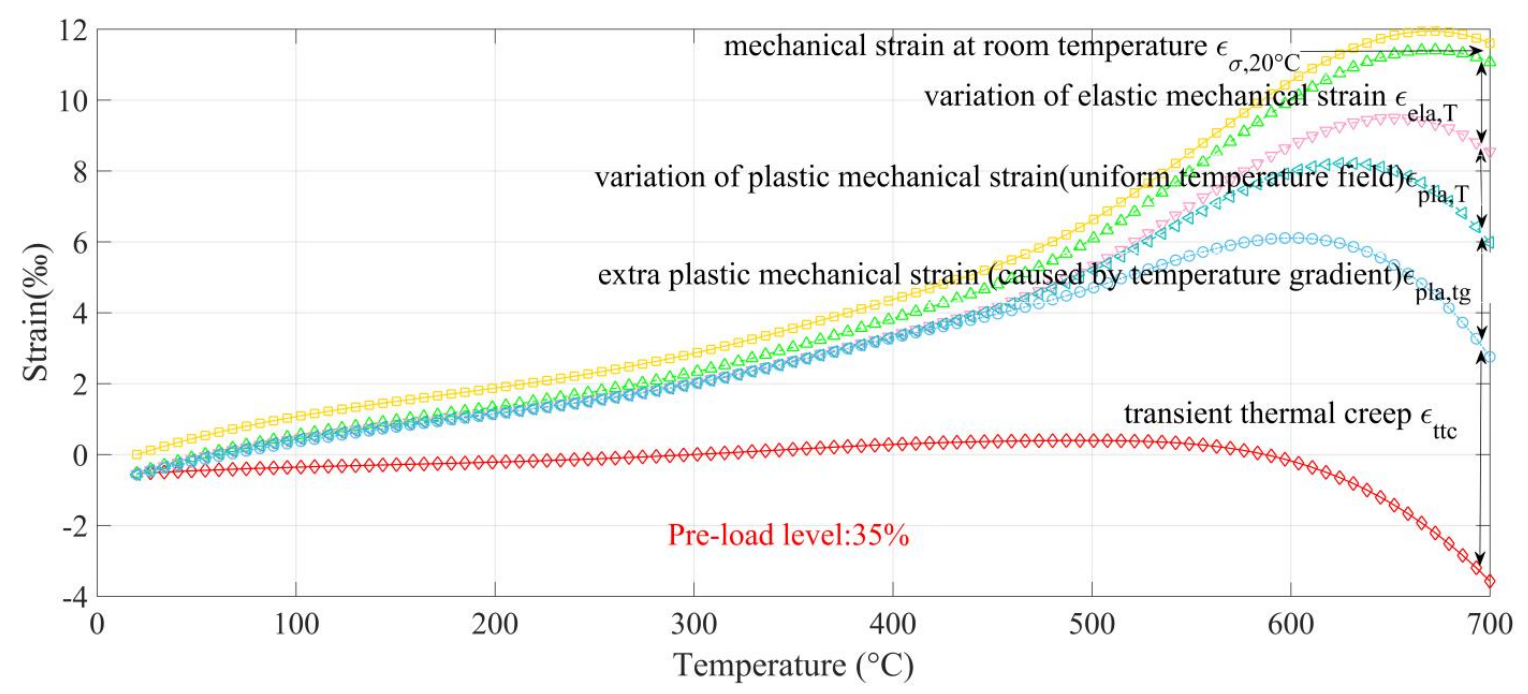

c. Loadlevel-35\% (case 5)

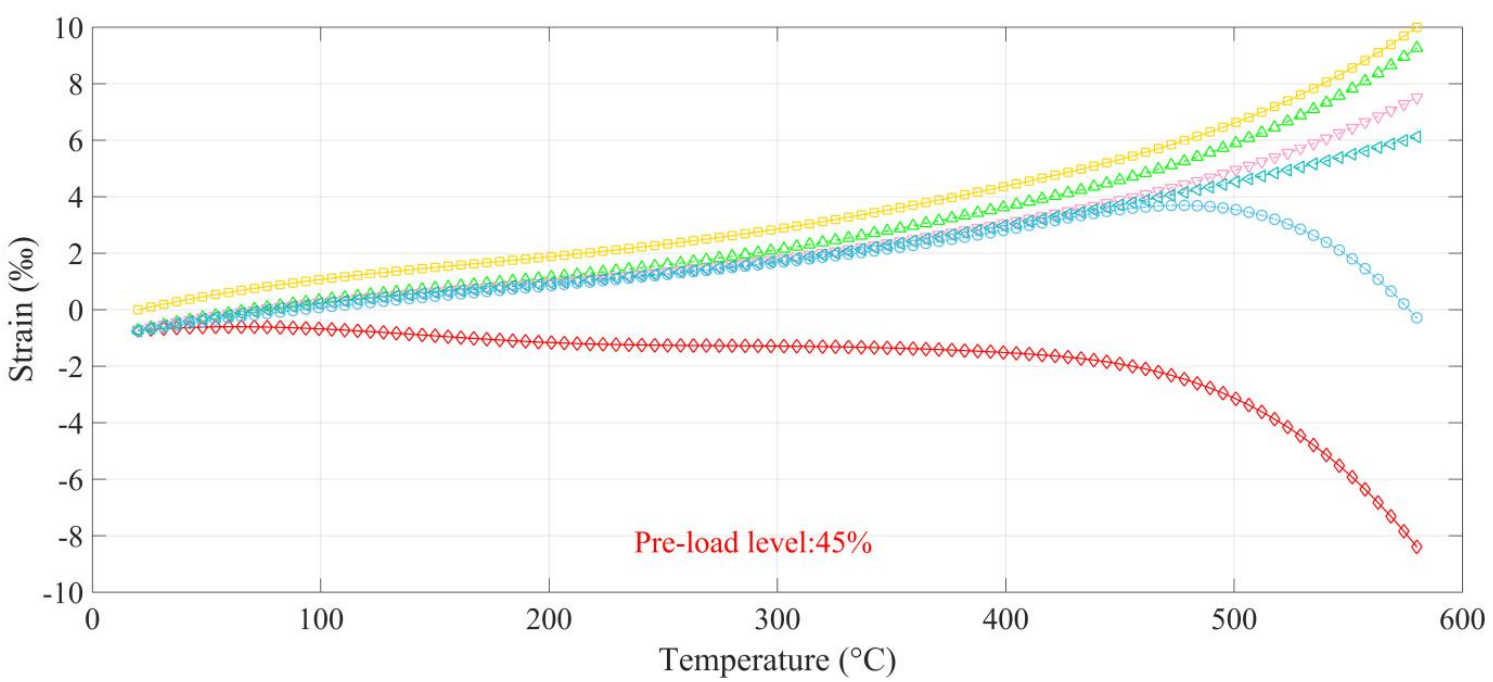

d. Loadlevel-45\% (case 6) 


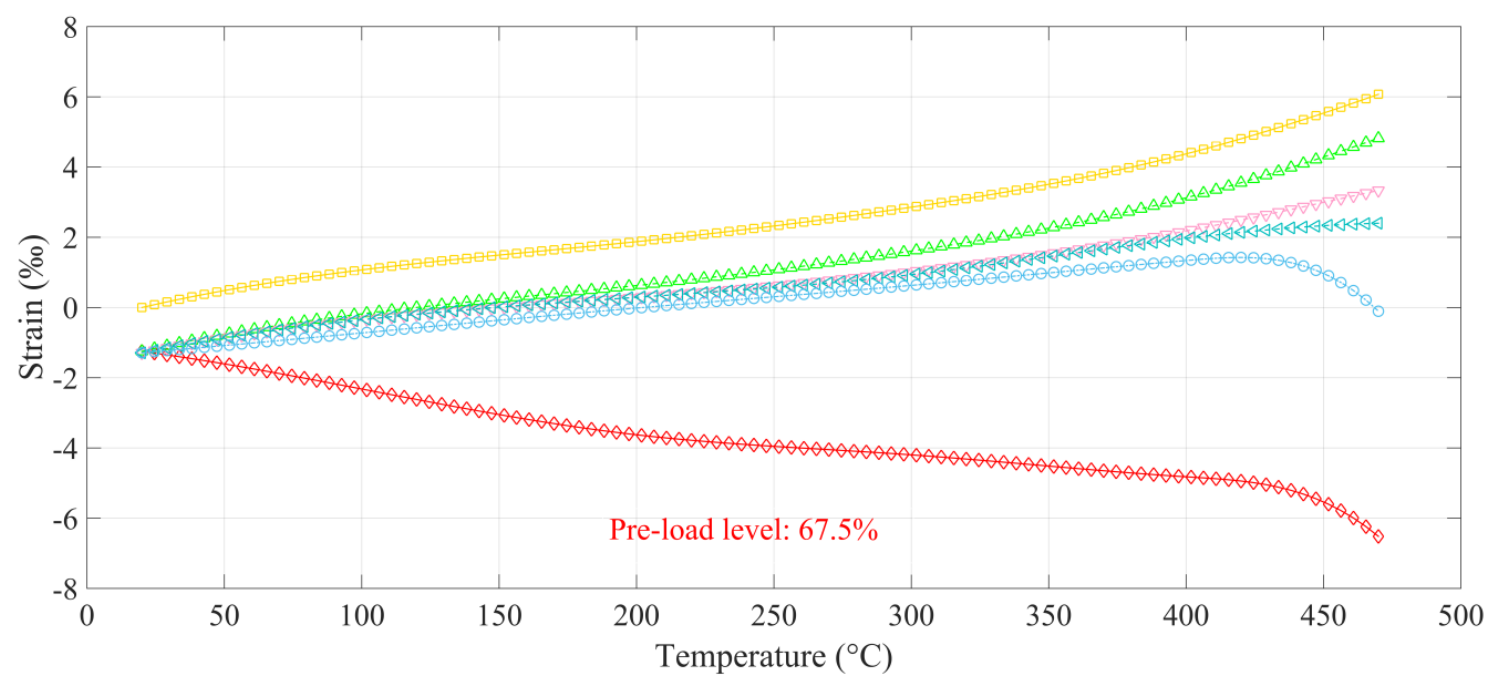

e. Loadlevel-67.5\% (case 7)

Fig.12 Strain decomposition and model comparison in transient test (cases 4-7)

According to Fig.12b-Fig. $12 \mathrm{e}$, before $400^{\circ} \mathrm{C}$, the mechanical strain parts ( $\varepsilon_{\text {ela } T}, \varepsilon_{\text {pla } T}$ and $\varepsilon_{p l a, t g}$ ) are very small when compared to the TTC at the same temperature. Hence, the results calculated by using different models are similar. However, after the temperature exceeds $450{ }^{\circ} \mathrm{C}$, the mechanical properties of concrete deteriorate sharply, which leads the quick increase of various mechanical strain parts and results in remarkable differences between different models, particularly when the temperature approaches to the crush point one. It is noted from the figure that the descending slope of the present numerical curve is almost parallel to the experimental curve, indicating that the sudden descending part of the total strain in the transient state test is likely attributed to the growth of the mechanical strain. It is evident from Fig.12 that the plastic strain caused by the temperature gradient is the dominant one among the mechanical strain parts. For example, at the end of case 6 (Fig.12d), the value of $\varepsilon_{\text {platg }}$ is larger than the sum of all other mechanical strain components and is almost the same as the magnitude of TTC. This implies that the TTC defined in many existing models actually includes some of mechanical strains, while the nature of the mechanical strain is completely different from that of TTC. 


\subsection{Refinement of TTC model}

According to abovementioned numerical results, TTC can be obtained by using a completely explicit method. By plotting $\varepsilon_{T T C} / \alpha_{l}$, the ratio of TTC to corresponding pre-load level $\alpha_{l}$, against temperature, a set of data is obtained, which is shown in Fig.13 as the red-dot points. By using the regression analysis, a refined formula of TTC is proposed:

$$
\varepsilon_{t t c}=\alpha_{l}\left(a\left(T-T_{0}\right)^{3}+b\left(T-T_{0}\right)^{2}+c\left(T-T_{0}\right)\right)
$$

where $a=1.076 \times 10^{-7}{ }^{\circ} \mathrm{C}^{-3}, b=-5.846 \times 10^{-5}{ }^{\circ} \mathrm{C}^{-2}, c=0.03109{ }^{\circ} \mathrm{C}^{-1}$.

The above model (red solid line) is plotted with Anderberg's model (Eq.(9) represented by blue solid line) in Fig.13. They both fit corresponding data very well and are very close to each other at early stage. As the analysis given in Table 1 and Sec.6.2, the TTC formulated by Anderberg has semi-implicitly included the plastic strain caused by temperature gradient in the transient state test. This is the reason why the value predicted by it is greater than that given by the explicit model. In Fig.13, the results given by two LITS models are also plotted for the purpose of comparison. The nonlinear LITS model of Diederichs (Eq.(4)) has the same form as the proposed TTC model, however, its parameters are calibrated by using semi-implicit method 1 rather than the explicit method. The value predicted by it has a good agreement with the two TTC models at relatively low temperature, but is overestimated at high temperature, which is caused by the inclusion of mechanical strains $\varepsilon_{\text {ela }, T}$ and $\varepsilon_{\text {pla,T }}$. The master LITS curve proposed by Khoury (Eq.(5)) gives a similar trend as Diederichs's model but with higher magnitude. In conclusion, the mechanical strain semi-implicitly included in existing TTC and LITS models can be an important part at a high temperature. Its inclusion in TTC result in obvious overestimation of TTC. 


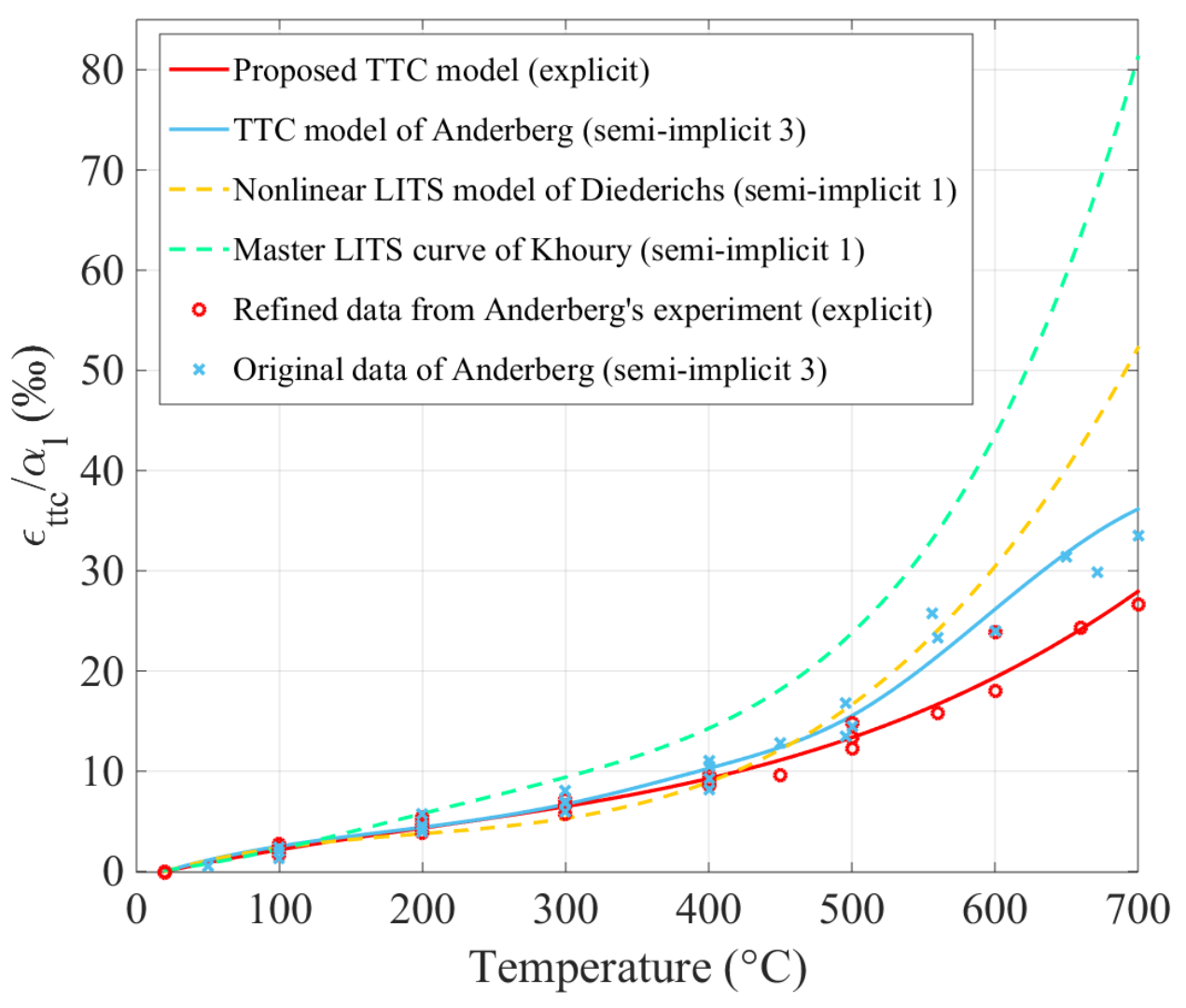

Fig.13 Comparison of different models

\subsection{Parametric study of heating rate and related temperature gradient in transient state test}

As discussed above, the temperature gradient in a transient state test not only results in stress fluctuation but also yields extra mechanical strain $\varepsilon_{p l a, t g}$, which can influence the evaluation of TTC. Since the temperature gradient in a concrete is heavily dependent on the situation where how the concrete is heated it is of interest to examine the sensitivity of the results to heating rate, which has also been proved to significantly influence the spalling of high-performance concrete under high temperature [37]. Cases $6,8,9,10$ are designed with the same pre-load level (45\%) but with different heating rates. The corresponding results are shown in Fig.14. As is demonstrated in the previous analysis, the reference point ( 0.7 times of radius) has smallest stress fluctuation because it is on the bisectrix of the area and thus the reference point is selected here as the place 
where the variation of results with temperature is examined.

It is shown in Figs. 14a and 14b that both the temperature gradient and stress fluctuation are very slight under the heating rate of $1{ }^{\circ} \mathrm{C} / \mathrm{min}$ and the corresponding strain calculated shown in Fig.14c is almost the same with that under homogeneous temperature field, indicating that the temperature gradient effect is negligible. With the increase of heating rate, however, both the temperature gradient and stress fluctuation become big, and at the same time, the temperature of crush point becomes low. This leads to large mechanical strain, as illustrated in Fig.14c, and thus great influence on the TTC.

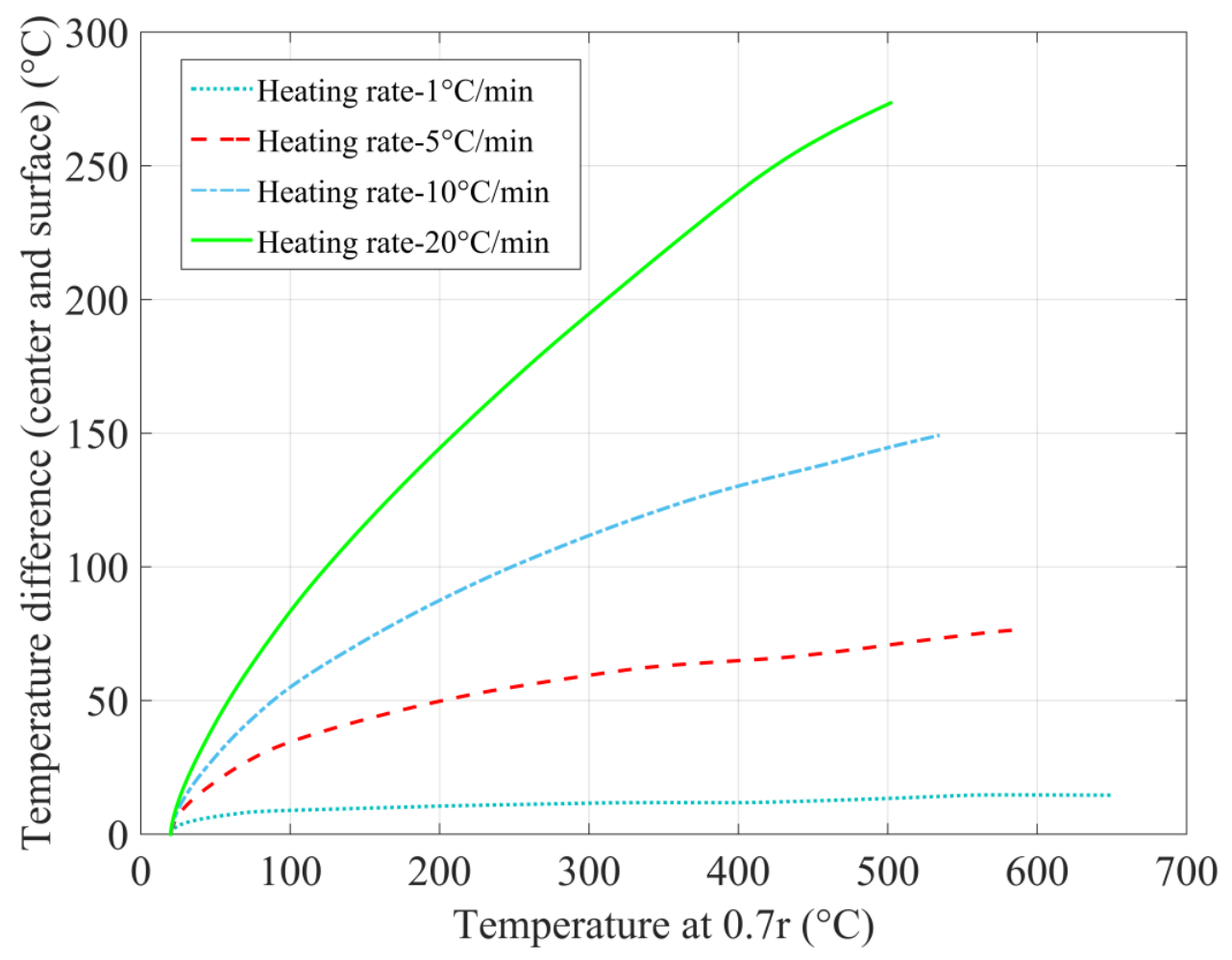

a. Temperature difference 


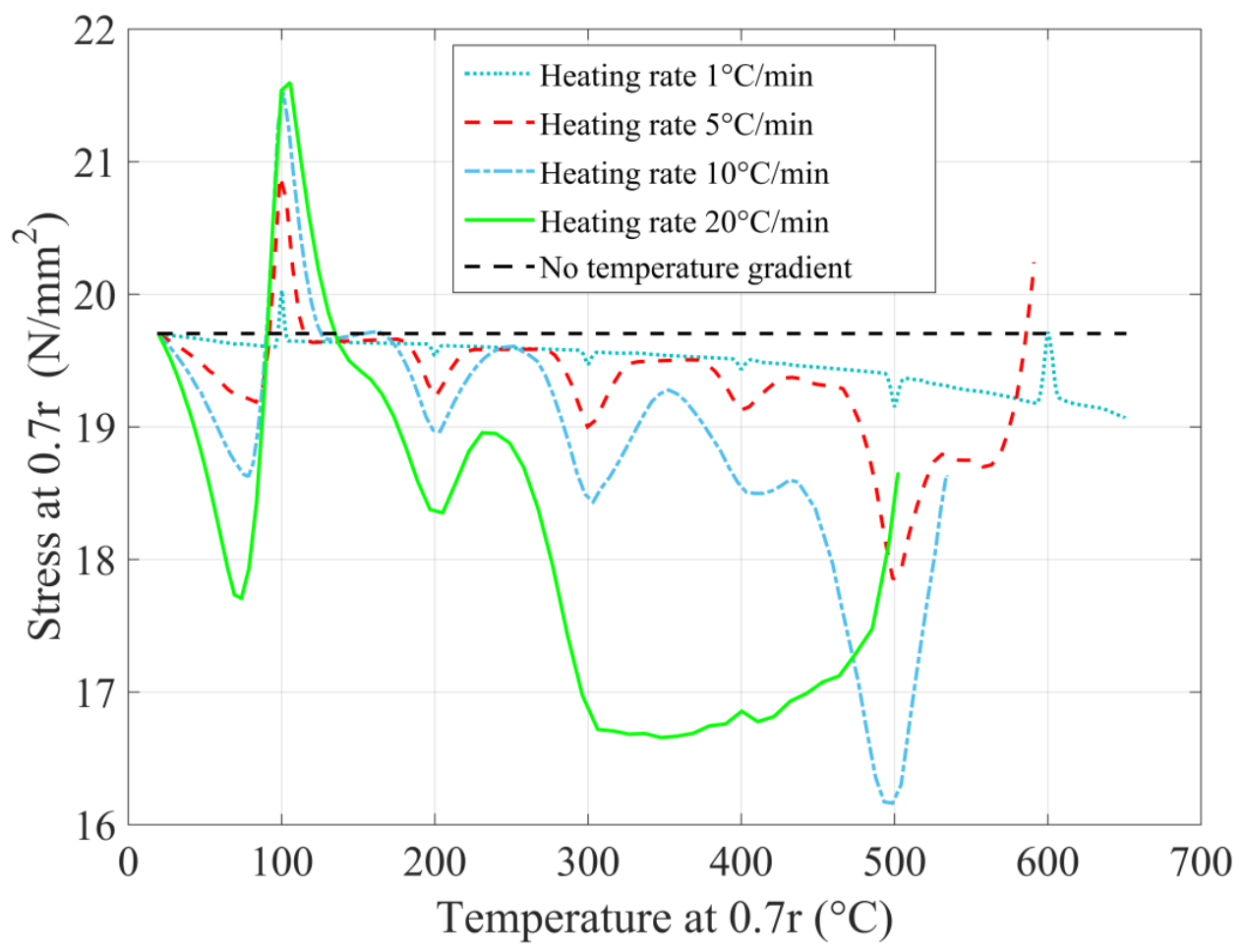

b. Stress fluctuation of reference point

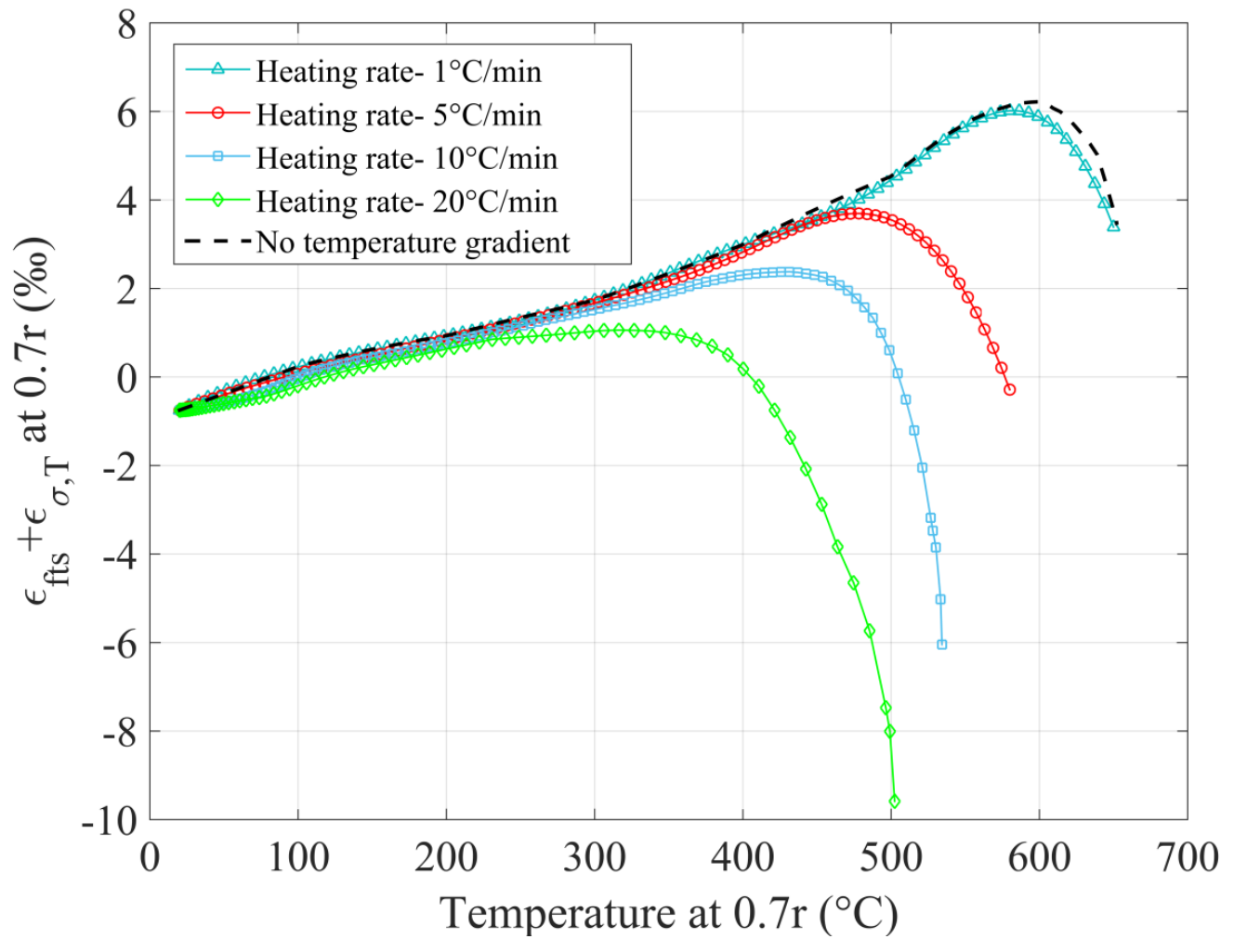

c. Strain development with time 
Fig.14 Parametric study of heating rate and related temperature gradient (cases $6,8,9,10$ )

\section{Conclusions}

In this paper, a numerical method has been developed to analyze the stress fluctuation and corresponding plastic strain caused by the combination of pre-fire load and temperature gradient. The results obtained have been compared with those calculated from existing models, from which the following conclusions can be drawn,

- The drawback of existing TTC and LITS models is the incomplete separation between TTC and mechanical strain, which makes it difficult to identify and understand the mechanism about how TTC is developed and what factors affect the evolution of TTC.

- Stress fluctuation is found in two opposite directions simultaneously due to the thermal gradient produced in the transient state test. At the early stage of exposure, the stress fluctuation is mainly controlled by the variation of thermal expansion. But at high temperature the deterioration of mechanical properties can have great influence on the stress fluctuation. The stress fluctuation can affect not only the evaluation of TTC but also the temperature of crush point.

- Extra mechanical strain can be produced by the thermal gradient in the transient state test, which has not been considered in previous models. At relatively high temperature this extra mechanical strain becomes very remarkable. The implicit inclusion of the extra mechanical strain in existing models is the reason for the observation of the sharp increase of TTC beyond $500{ }^{\circ} \mathrm{C}$ in many previous works.

- The explicit numerical model proposed in this study can accurately evaluate the TTC on the base of experimental results and can calculate the different parts of 
mechanical strain, especially the one caused by the thermal gradient.

- As an example, a recalibration is accomplished by applying the present explicit model to Anderberg's experimental study. The results demonstrated that ignoring the effect of temperature gradient could lead an overestimation of TTC, particularly when the temperature is high.

- The effect of temperature gradient on the evolution of mechanical strain can be neglected in the transient state test if the maximum temperature does not exceed $400{ }^{\circ} \mathrm{C}$ or if the heating rate is very low.

\section{Acknowledgement}

The first author would like to acknowledge the financial support received from the China Scholarship Council and University of Plymouth for his Ph.D. study at University of Plymouth. Part of the present work was also supported by the European Commission Research Executive Agency via a Marie Skłodowska-Curie Research and Innovation Staff Exchange project (689857-PRIGeoC-RISE-2015).

\section{Declarations of interest}

None

\section{References}

[1] Y. Anderberg, S. Thelandersson, Stress and deformation characteristics of concrete at high temperatures, Lund Institute of Technology, Lund, 1976.

[2] U. Schneider, Behaviour of concrete under thermal steady state and non - steady state conditions, Fire Mater. 1 (1976) 103-115.

[3] G.A. Khoury, B.N. Grainger, P.J. Sullivan, Transient thermal strain of concrete: 
literature review, conditions within specimen and behaviour of individual constituents, Mag. Concr. Res. 37 (1985) 131-144.

[4] G. Torelli, P. Mandal, M. Gillie, V.-X. Tran, Concrete strains under transient thermal conditions: A state-of-the-art review, Eng. Struct. 127 (2016) 172-188.

[8] L.Y. Li, J. Purkiss, Stress-strain constitutive equations of concrete material at elevated temperatures, Fire Saf. J. 40 (2005) 669-686.

[9] J. Purkiss, L.Y. Li, third ed., Fire safety engineering design of structures, CRC Press, London, 2013.

[10] V. Kodur, S. Alogla, Effect of high-temperature transient creep on response of reinforced concrete columns in fire, Mater. Struct. 50 (2017) 27.

[11] R. Johansen, C.H. Best, Creep of concrete with and without ice in the system, Bull RILEM. 16 (1962) 47-57.

[12] G.A. Khoury, B.N. Grainger, P.J. Sullivan, Strain of concrete during first heating to $600{ }^{\circ} \mathrm{C}$ under load, Mag. Concr. Res. 37 (1985) 195-215.

[13] G.A. Khoury, B.N. Grainger, P.J.E. Sullivan, Strain of concrete during first cooling from $600{ }^{\circ} \mathrm{C}$ under Load, Mag. Concr. Res. 38 (1986) 3-12.

[14] C. Castillo, Effect of transient high temperature on high-strength concrete, Rice University, Houston, 1987.

[15] M. Abid, X. Hou, W.Zheng, R.Hussain, High temperature and residual properties of reactive powder concrete - A review, Constr. Build. Mater. 147 (2017) 339-351.

[16] S. Hassen, H. Colina, Transient thermal creep of concrete in accidental conditions at temperatures up to $400{ }^{\circ} \mathrm{C}$, Mag. Concr. Res. 58 (2006) 201.

[17] M. Petkovski, R. Crouch, Strains under transient hygro-thermal states in concrete loaded in multiaxial compression and heated to $250{ }^{\circ} \mathrm{C}$, Cem. Concr. Res. 38 (2008) 586-596. 
[18] J.-C. Mindeguia, I. Hager, P. Pimienta, H. Carré, C. La Borderie, Parametrical study of transient thermal strain of ordinary and high performance concrete, Cem. Concr. Res. 48 (2013) 40-52.

[19] Z. Pan, J.G. Sanjayan, F. Collins, Effect of transient creep on compressive strength of geopolymer concrete for elevated temperature exposure, Cem. Concr. Res. 56 (2014) 182-189.

[20] W.D.A. Rickard, G.J.G. Gluth, K. Pistol, In-situ thermo-mechanical testing of fly ash geopolymer concretes made with quartz and expanded clay aggregates, Cem. Concr. Res. 80 (2016) 33-43.

[21] G.A. Khoury, Transient thermal creep of nuclear reactor pressure vessel type concretes, Imperial College London, London, 1983.

[22] M.J. Terro, Numerical modelling of the behaviour of concrete structures in fire, ACI Struct. J. 95 (1998) 183-193.

[23] G. Khoury, Strain of heated concrete during two thermal cycles. Part 1: strain over two cycles, during first heating and at subsequent constant temperature, Mag. Concr. Res. 58 (2006) 367-385.

[24] T. Gernay, J.M. Franssen, A formula of the Eurocode 2 concrete model at elevated temperature that includes an explicit term for transient creep, Fire Saf. J. 51 (2012) 19 .

[25] U. Schneider, Concrete at high-temperatures - a general review, Fire Saf. J. 13 (1988) 55-68.

[26] Eurocode2: Design of concrete structures-Part 1-2: General rules-Structural fire design, Brussels, 2004.

[27] C. Nielsen, C. Pearce, N. Bićanić, Theoretical model of high temperature effects on uniaxial concrete member under elastic restraint, Mag. Concr. Res. 54 (2002) 239249.

[28] U. Diederichs, Modelle zur Beschreibung der Betonverformung bei instantionaren Temperaturen, Abschlubkolloquium Bauwerke Unter Brandeinwirkung, (1987) 25-34.

[29] Eurocode2: Design of concrete structures-Part 1-2: General rules-Structural fire design, European Prestandard, Brussels, 1995. 
[30] T. Gernay, Effect of transient creep strain model on the behavior of concrete columns subjected to heating and cooling, Fire Technol. 48 (2012) 313-329.

[31] F. Furumura, T. Abe, Y. Shinohara, Mechanical properties of high strength concrete at high temperatures, Proceedings of the Fourth Weimar Workshop on High Performance Concrete: Material Properties and Design, (1995) 237-254.

[32] U. Schneider, M. Schneider, An advanced transient concrete model for the determination of restraint in concrete structures subjected to fire, J Adv. Concr. Technol. 7 (2009) 403-413.

[33] A. Khennane, G. Baker, Uniaxial model for concrete under variable temperature and stress, J. Eng. Mech. 119 (1993) 1507-1525.

[34] U. Schneider, G. Kassel, Properties of materials at high temperatures: concrete, University of Kassel, Kassel, 1985.

[35] Y. Wang, I. Burgess, F. Wald, M. Gillie, Performance-based fire engineering of structures, CRC Press, London, 2012.

[36] O. Bahr, P. Schaumann, B. Bollen, J. Bracke, Young's modulus and Poisson's ratio of concrete at high temperatures: Experimental investigations, Mater. Des. 45 (2013) 421-429.

[37] J. Zhao, J. Zheng, G. Peng, K. Breugel, Numerical analysis of heating rate effect on spalling of high-performance concrete under high temperature conditions, Constr. Build. Mater. 152 (2017) 456-466. 